LBNL-52493

\title{
Reactive Geothermal Transport Simulation to Study the Formation Mechanism of Impermeable Barrier between Acidic and Neutral Fluid Zones in the Onikobe Geothermal Field, Japan
}

Norifumi Todaka and Chitoshi Akasaka

Engineering Department, Electric Power Development Co., Ltd., Tokyo, 104-8165 Japan

Tianfu Xu and Karsten Pruess

Earth Science Division, Lawrence Berkeley National Laboratory, University of California, Berkeley, CA 94720, USA

March 2003

This work was supported partly by a project provided Electric Power Development Co., Ltd. (Japan), and partly by the Assistant Secretary for Energy Efficiency and Renewable Energy, Office of Wind and Geothermal Technologies, of the U.S. Department of Energy, under Contract No. DE-AC03-76SF00098. 


\title{
Reactive Geothermal Transport Simulation to Study the Formation Mechanism of Impermeable Barrier between Acidic and Neutral Fluid Zones in the Onikobe Geothermal Field, Japan
}

\author{
Norifumi Todaka and Chitoshi Akasaka \\ Engineering Department, Electric Power Development Co., Ltd., Tokyo, 104-8165 Japan
}

Tianfu Xu and Karsten Pruess

Earth Science Division, Lawrence Berkeley National Laboratory, University of California, Berkeley, CA 94720 , USA

\section{Introduction}

The Onikobe geothermal field in the Miyagi Prefecture, north-central Honshu, Japan, has been developed by Electric Power Development Co., Ltd. (EPDC). Power plant operation at a rated capacity of 9 MW began in 1975. Output was increased to $12.5 \mathrm{MW}$ in 1976. In the investigation stage, the pH 2.6 water of well GO-11 drilled in the central area caused a blow-out and ejected corroded casing after four months of production (Abe, 1988). The production in this field comes from a shallow reservoir developed initially to avoid the strongly acid fluid. Several years later, however, production wells have been deviated to deep, high $\mathrm{pH}$, production zones away from the central acidic upflow zone because of rapid pressure depletion and declining enthalpy in a shallow reservoir.

Two types of fluids are encountered in the Onikobe deep geothermal reservoir (Akasaka et al., 2001), one is neutral and the other is acidic $(\mathrm{pH}=3)$. The acidic fluid is characterized by higher concentrations of $\mathrm{Mg}, \mathrm{Fe}, \mathrm{Pb}, \mathrm{Zn}$, and $\mathrm{Cl}$ compared with the neutral one. The two types of fluids are locally isolated from one another. Based on a relationship between the acidic fluid zone and acidic alteration (pyrophyllite) zone, it is determined that acidic fluid might be upwelling along the fault that forms the horst structure.

Some experience about mineral precipitation by fluid-fluid mixing has been obtained by Todaka and Tezuka (2002). Mn-rich smectite scale coexisting with sulfides formed inside some production wells by mixing of acidic and neutral fluids from two feed zones, and silica scale formed by mixing in the surface pipeline. Moreover, sphalerite and galena scales are deposited inside the production well. Reservoir fluid mixed with re-injected water might be supersaturated with respect to sphalerite and galena. In order to confirm the precipitation of these minerals by fluid-fluid mixing, simulation was performed by the chemical equilibrium approach (Ajima et al., 1998; Todaka and Tezuka, 2002) using SOLVEQ/CHILLER (Reed, 1982).

Mineral precipitation at the mixing front of acidic and neutral fluids in the natural state and also in 
the exploitation (production and re-injection) stage in the reservoir, may form an impermeable barrier, resulting in changes of the overall formation permeability. Such phenomena may be the reason why acidic and neutral fluids are clearly separated in the same reservoir. Reactive chemical transport simulation was carried out to test the formation mechanism of an impermeable barrier between acidic and neutral fluid zones and to understand geochemical and hydrogeological changes due to exploitation. Simulated mineral precipitation agrees well with field observation of Onikobe.

\section{Conceptual model of Onikobe geothermal system}

\subsection{Geology and geothermal reservoir}

The Onikobe geothermal field is located within the $8 \mathrm{~km}$ diameter Onikobe basin, in the Backbone Range of northern Honshu, Japan. The Onikobe basin (probably caldera) is characterized by a circular depression bounded by a series of ring faults and by a structural dome whose axis is NW-SE inside the basin. The depression was formed after accumulation of the Miocene formations which are represented by "Green Tuff". According to Yamada (1988), the Onikobe caldera was formed by collapse after eruptions of voluminous dacitic ash flows about 1.7-2.7 million years ago.

The geology around the Onikobe power plant consists of the Pre-tertiary granodiorite, the Kanisawa Formation of Miocene, and the Sannozawa formation, the Ofukazawa andesite member of the Akazawa Formation and the Takahinata-yama Dacite of Pleistocene (Figure 2.1). The granodiorite is confirmed at a depth of about $1200 \mathrm{~m}$ at the Onikobe geothermal power plant by some exploratory wells. The Kanisawa Formation is underlain by Mesozoic granite basement. The Kanisawa Formation is caldera basement which is the Miocene "Green Tuff" (the upper part: mainly andesite lava, the lower part: mainly pyroclastics). This formation distributes at a depth from $700 \mathrm{~m}$ to $1500 \mathrm{~m}$.

The post-caldera volcanism of the Pleistocene took place within the caldera. The Sannozawa formation made of altered dacitic tuff breccia has low permeability. A two-phase geothermal reservoir is formed in the Ofukazawa andesite member (the Akazawa Formation) made of andesite lava and tuff breccia shallower than $500 \mathrm{~m}$ in depth. The Takahinata-yama Dacite is the youngest volcanic rock (0.24-0.35 Ma) and is considered to be heat source in this field.

Two phase zone in the reservoir, shallower than $300 \mathrm{~m}$ in depth, is formed in the Ofukazawa andesite member. A water-dominated geothermal reservoir is mainly formed in the Kanisawa Formation, especially in vertical fractures caused by a local horst structure (relating to the NW-SE dome structure) with a temperature of around $250^{\circ} \mathrm{C}$. This is a main production zone of the Onikobe geothermal power plant at present.

Acidic alteration zones (pyrophyllite) are distributed along the horst faults. The distribution of acidic fluid agrees well with that of acidic alteration. Based on this relationship, it is determined that 
acidic fluid might be upwelling along the faults that form the horst structure, and then is mixed with the original reservoir fluid (neutral).

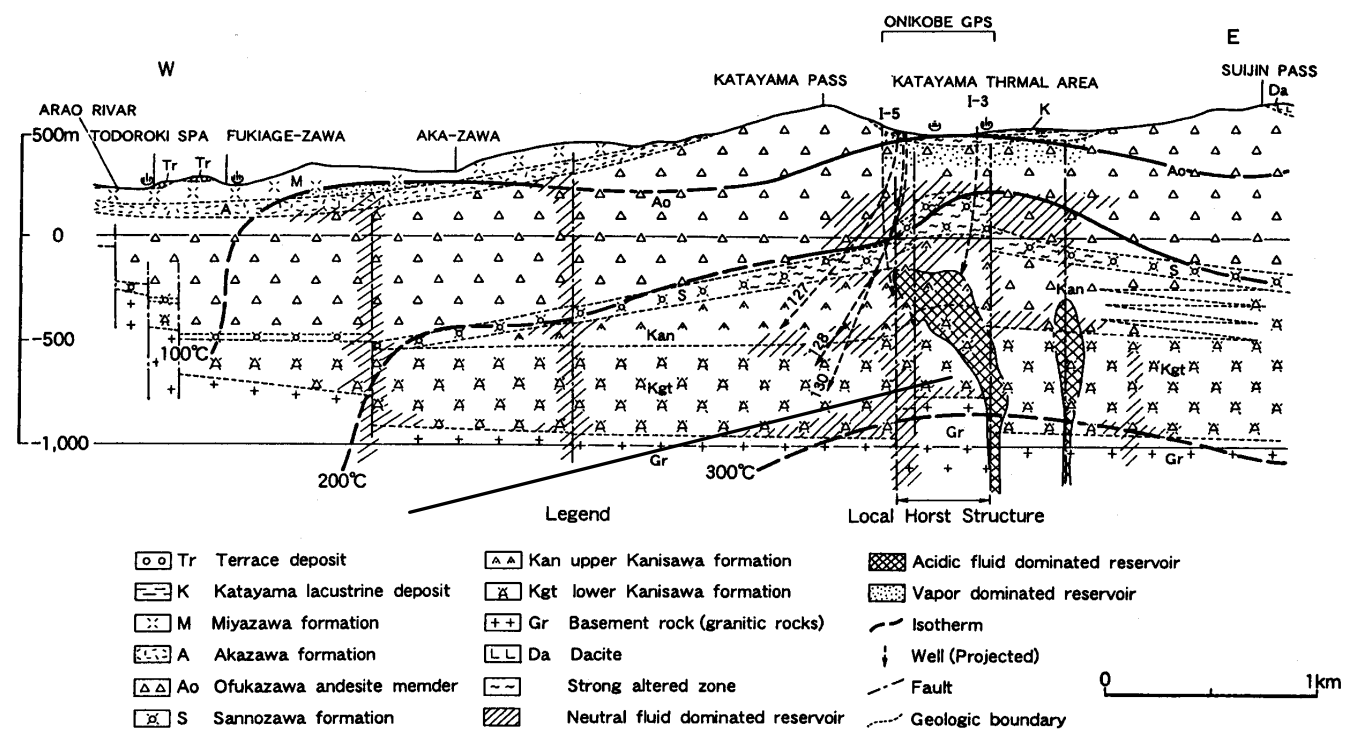

Figure 2.1 Geothermal system around the Onikobe geothermal power plant

\subsection{Temperature distribution}

Figure 2.2 shows the subsurface temperature profiles of wells in the production area and the surrounding area. The temperature profiles of wells can be classified into three types; "upflow type", "recharge type" and "conduction type". A zone showing the upflow type profiles is distributed at the center of the Onikobe geothermal field (the Onikobe power plant), while the recharge type area is distributed in the surrounding area. The formation temperatures reach $250^{\circ} \mathrm{C}$ at elevation $-500 \mathrm{~m}$ (Figure 2.3), except the conduction type area in which KR-5 and KR-6 along the ring structure of the Onikobe basin are located. $288^{\circ} \mathrm{C}$ has been measured in well GO-11, at elevation $-750 \mathrm{~m}$ in the central area. In the south of the power plant, the maximum temperature in this field is $313.6^{\circ} \mathrm{C}$ at elevation $-930 \mathrm{~m}$ (well KR-4). 


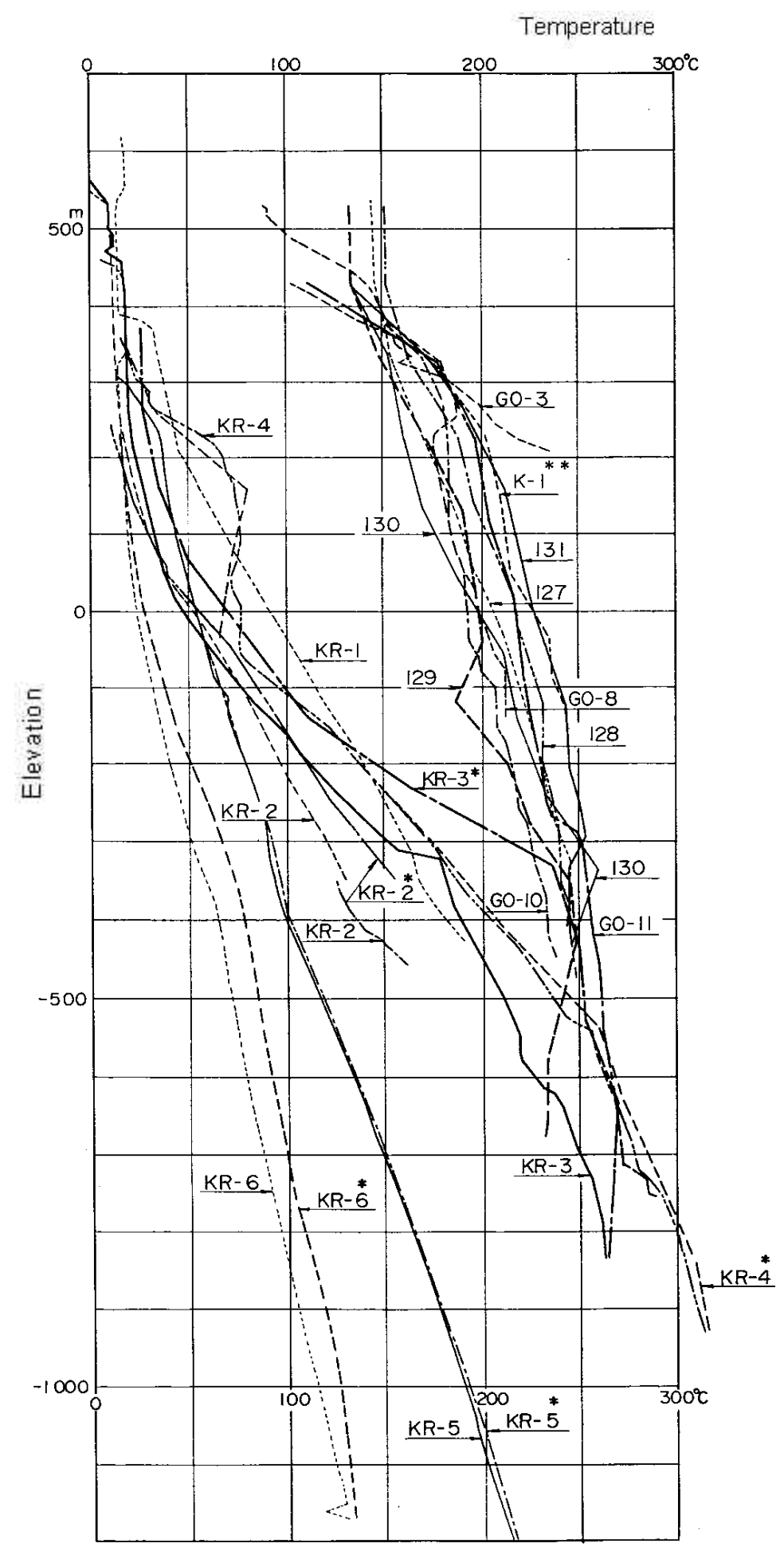

Figure 2.2 Temperature profiles of wells in the Onikobe geothermal field 


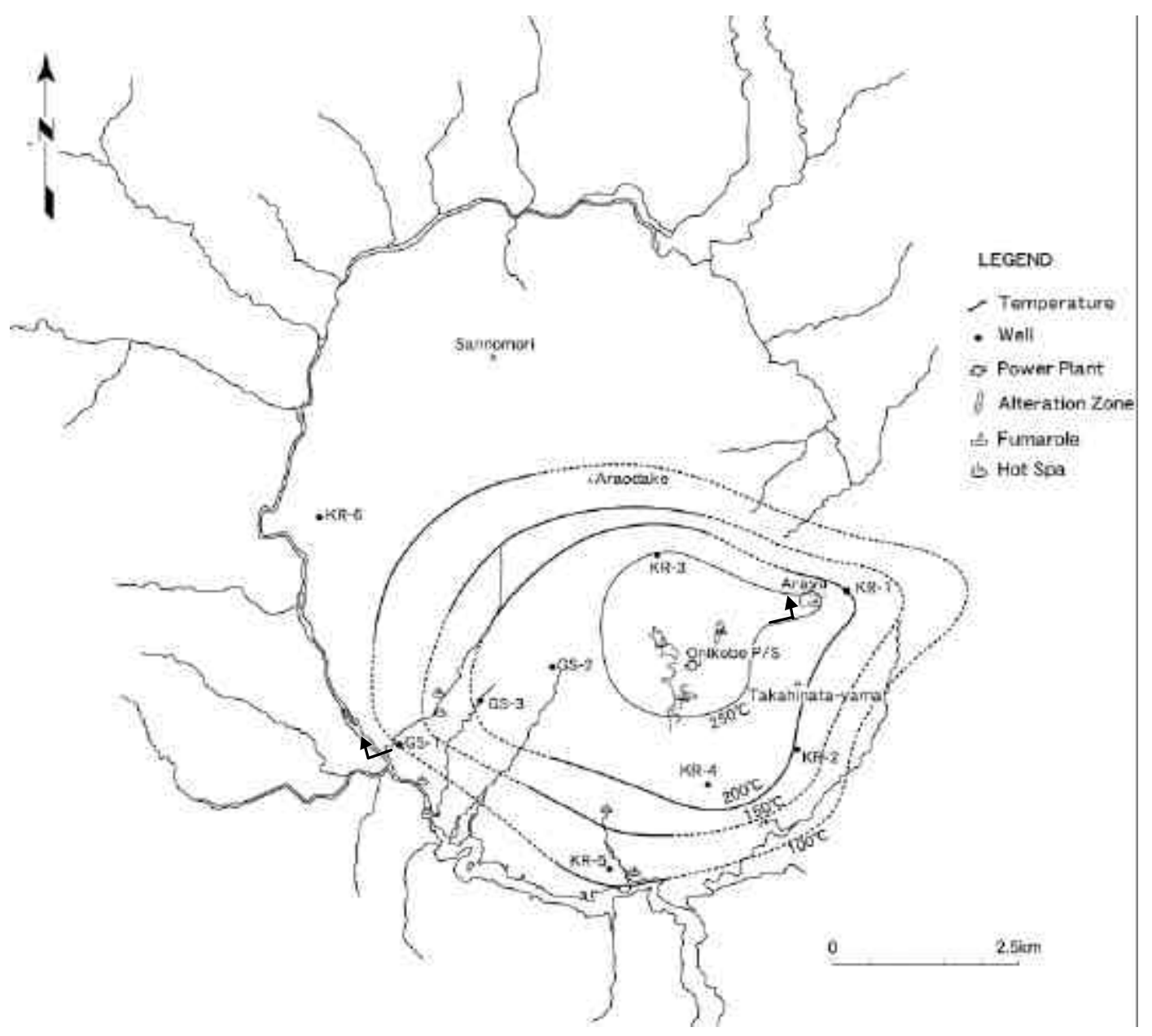

Figure 2.3 Temperature distribution at elevation $-500 \mathrm{~m}$

\subsection{Fluid geochemistry}

The chemical compositions of separated waters from the Onikobe production wells are shown in Table 2.1. The chemical compositions of the production fluids at Onikobe vary widely but have certain characteristics in common. The largest variations in concentration are in $\mathrm{pH}$ and acid sensitive constituents including $\mathrm{Fe}, \mathrm{Mg}, \mathrm{Ca}$ which are dissolved from reservoir rocks and casings by low $\mathrm{pH}$ waters and other constituents with volatility depending on $\mathrm{pH}\left(\mathrm{NH}_{4}, \mathrm{HBO}_{3}\right)$. The $\mathrm{pH}$ varies from 2.8 to 7.8 and $\mathrm{Fe}$ varies from 0.05 to $371 \mathrm{mg} / \mathrm{l}$. The fluids are grouped into acidic fluid with a pHof about 3 and neutral fluid with a pH between 6.7 and 7.8.

Acidic and neutral fluids are locally isolated from one another (Figure 2.4). The acidic reservoir seems to be limited to intermediate-deep depths close to the central area such as wells 128 (intermediate feed zone), 130 (intermediate feed zone), 131, 133, GO-10 and GO-11. Neutral waters 
with low salinity are produced from relatively deep horizons penetrated by wells deviated away from the center such as wells 127, 128 (deep feed zone), 129, 130 (deep feed zone), 132, 134 and 135. There is a consistent increase in salinity with time along with indications that the waters are gas depleted. These observations are interpreted as showing that injected waters enriched in salts and depleted in gases are contributing to production waters.

Acidic waters in geothermal reservoirs can come from two directions, either from below as incompletely neutralized volcanic fluids, or from above as a result of downflow of acid sulfate waters formed by atmospheric oxidation of $\mathrm{H}_{2} \mathrm{~S}$ carried into the aerated zone by upflowing steam. According to Truesdell and Todaka (2001), it is likely that the acidic waters result from incomplete neutralization of $\mathrm{HCl}$ carried in superheated volcanic steam, because the acidic water has low $\mathrm{SO}_{4} / \mathrm{Cl}$ ratio and the acidic waters have higher chloride than the neutral waters. In addition, clearly there is a large excess of chloride (defined as chloride greater than that required to electrically balance all the positively charged ions in solution without counting hydrogen) in the acidic waters. This is proof that at least some of the acidity is caused by $\mathrm{HCl}$ rising into the geothermal system from magmatic source at greater depth. Part of the acidity may have come from sulphuric acid (of volcanic or surface origin) but not enough to affect the chloride "excess".

Table 2.1 Chemical composition of separated waters from the Onikobe production wells

\begin{tabular}{crrr} 
& & & $(\mathrm{mg} / \mathrm{l})$ \\
\hline & \multicolumn{2}{c}{ Acidic water } & \multicolumn{2}{c}{ Neutral water } \\
\hline $\mathrm{pH}$ & $2.8-5.0$ & $6.7-7.8$ \\
$\mathrm{H}_{2} \mathrm{~S}$ & \multicolumn{2}{c}{$<0.5$} & $<0.5-2.1$ \\
$\mathrm{~T}^{-\mathrm{CO}_{2}}$ & \multicolumn{2}{c}{$<10$} & \multicolumn{2}{c}{$<10$} \\
$\mathrm{Cl}$ & $4300-5650$ & $2160-4840$ \\
$\mathrm{SO}_{4}$ & $19.7-50.0$ & $14.7-23.9$ \\
$\mathrm{Na}$ & $1850-2240$ & $1100-2170$ \\
$\mathrm{~K}$ & $345-435$ & $198-355$ \\
$\mathrm{Ca}$ & $474-721$ & $179-650$ \\
$\mathrm{Mg}$ & $8.38-58.3$ & $0.31-5.51$ \\
$\mathrm{Fe}$ & $1.55-371$ & $0.05-0.32$ \\
$\mathrm{Al}$ & $0.04-0.43$ & $0.15-0.21$ \\
$\mathrm{SiO}$ & $527-725$ & $613-695$ \\
$\mathrm{~B}$ & $62.4-80.9$ & $43.5-78.2$ \\
$\mathrm{As}$ & $0.57-1.77$ & $0.47-0.58$ \\
\hline \multicolumn{5}{c}{ *Sampling: December, 1998}
\end{tabular}




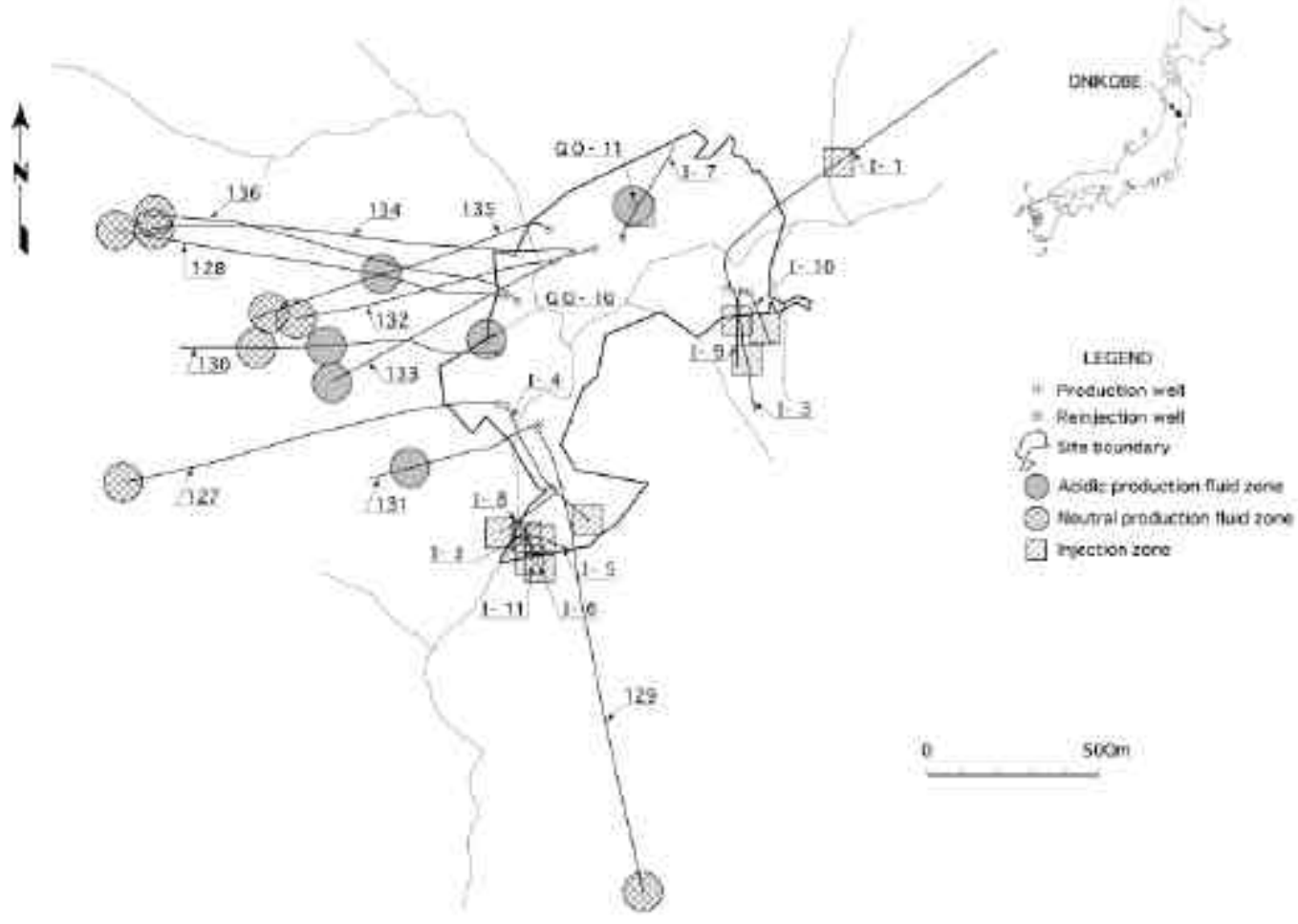

Figure 2.4 Location map showing main feed zones of acidic and neutral fluids

\section{Numerical method}

Modeling of reactive geochemical transport at the Onikobe geothermal field was performed using the reactive transport computer code TOUGHREACT (Xu and Pruess, 1998 and 2001). The code uses a sequential iteration approach similar to Yeh and Tripathi (1991), Walter et al. (1994), and Xu et al. (1999), which solves the transport and reaction equations separately. Flow and transport are based on space discretization by means of integral finite differences (Narasimhan and Witherspoon, 1976). An implicit time-weighting scheme is used for the individual components of the model consisting of flow, transport, and kinetic geochemical reactions. The chemical transport equations are solved independently for each component, whereas the reaction equations are solved on a grid-block basis using Newton-Raphson iteration. Full details of the code are given in Xu and Pruess (1998 and 2001).

In the model, advective and diffusive transport of aqueous chemical species are considered. Aqueous chemical complexation is considered assuming local equilibrium. Mineral dissolution/precipitation can proceed at equilibrium and/or under kinetic conditions. Temperature effects are also considered for geochemical reaction calculations because equilibrium and kinetic data are functions of temperature. 
In the present work, we neglect the following: (1) compaction and thermal mechanics, such as micro-fracturing by thermal stress and hydro-fracturing by thermal expansion of pore fluid; (2) the effect of chemical concentration changes on fluid thermo-physical properties such as density and viscosity which are otherwise primarily dependent on pressure and temperature; (3) the enthalpy due to chemical reactions.

One-dimensional and two-dimensional simulations were carried out to understand chemical and physical phenomena by fluid mixing. Non-flow and flow simulations in one-dimensional models are carried out in this work. Calculations between two kinds of one-dimensional simulations and two-dimensional simulation are iterated to be consistent with the field data (Figure 3.1).

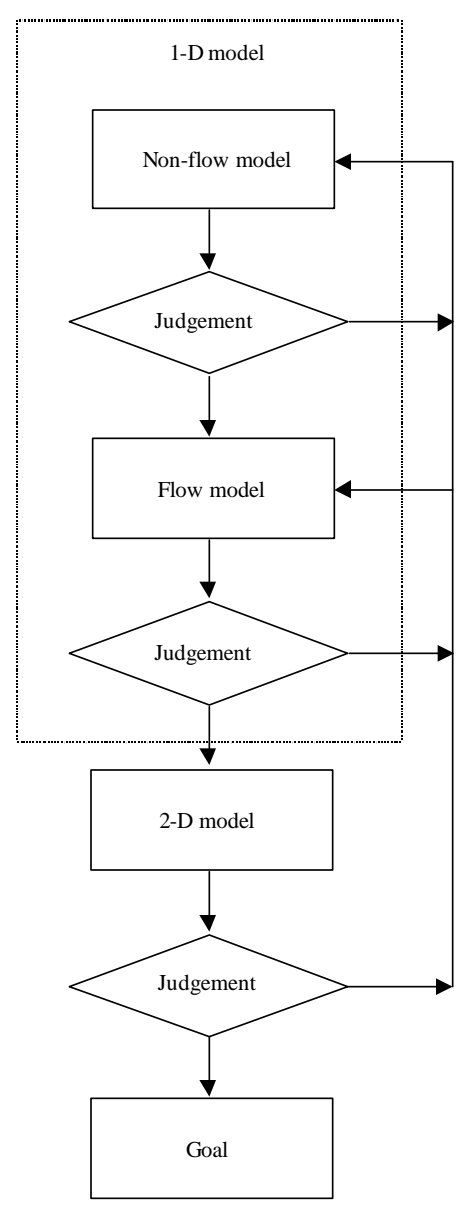

Figure 3.1 Simulation flow chart 


\section{Hydrogeological and Geochemical Conditions}

\subsection{Hydrogeological Conditions}

\subsubsection{One-dimensional model}

One-dimensional porous medium numerical models were used to verify the geochemical behavior due to mixing of acidic and neutral fluids. Schematic representations are shown in Figures 4.1, and 4.2 for the non-flow and flow models. Common rock properties in the models are as follows; grain density: $2750 \mathrm{~kg} / \mathrm{m}^{3}$, porosity: 0.1 , permeability: $20 ? 10^{-15} \mathrm{~m}^{2}$, thermal conductivity: $3 \mathrm{~W} /\left(\mathrm{m}^{\circ} \mathrm{C}\right)$, heat capacity: $1000 \mathrm{~J} /\left(\mathrm{kg}^{\circ} \mathrm{C}\right)$. The flow model was run in isothermal as well as non-isothermal conditions. To study temperature effect, three different temperatures $\left(230,250\right.$ and $\left.270^{\circ} \mathrm{C}\right)$ were considered in the isothermal flow model. The temperature range and pressure used were from field data. The number of grid blocks was increased from 10 in the non-flow model to 100 in the flow model, to show chemical reactive behavior occurring with flow path in detail. Darcy velocity was set to $1 \mathrm{~mm} / \mathrm{day}$ in all flow models by specification of the mass source in the left boundary block. A linear temperature gradient from $290^{\circ} \mathrm{C}$ to $210^{\circ} \mathrm{C}$ is assumed in non-isothermal flow model, to evaluate temperature effects in reactive transport.

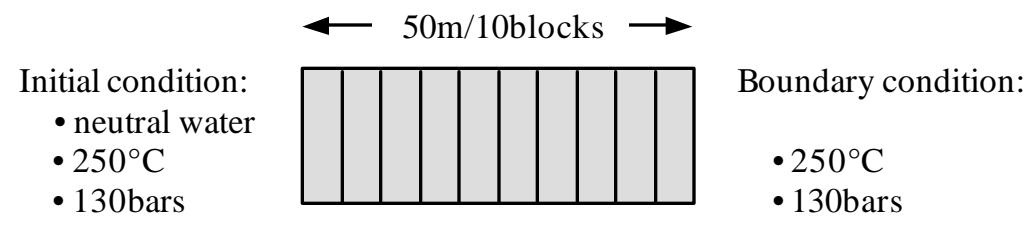

Figure 4.1 Schematic representation of non-flow model 


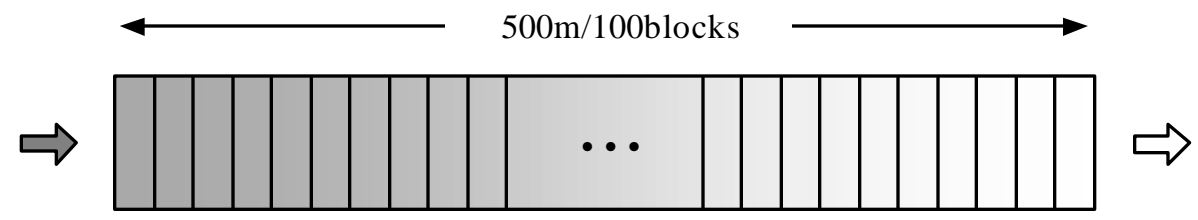

Mass source:

- acidic water

- $250^{\circ} \mathrm{C}$

- $1 \mathrm{~mm} / \mathrm{day}$

Initial condition:

Boundary condition:

- neutral water

- $250^{\circ} \mathrm{C}$

- $250^{\circ} \mathrm{C}$

-130bars

- 129bars

(a) Isothermal

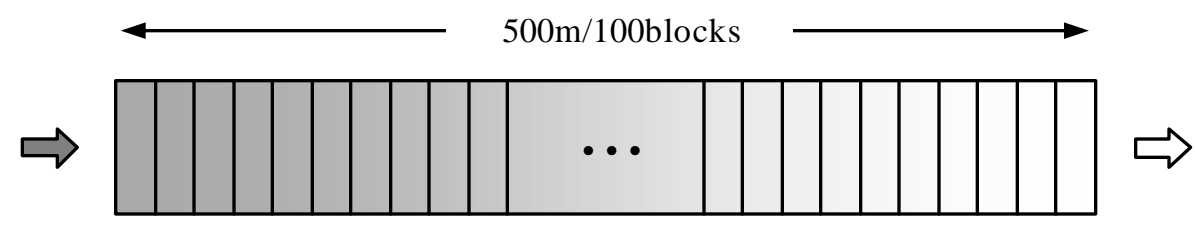

Mass source:

- acidic water

- $290^{\circ} \mathrm{C}$

$\cdot 1 \mathrm{~mm} /$ day
Initial condition:

- neutral water

- $250^{\circ} \mathrm{C}$

-130bars
Boundary condition:

- $210^{\circ} \mathrm{C}$

-129bars

(b) Non-isothermal

Figure 4.2 Schematic representation of one-dimensional flow models 


\subsubsection{Two-dimensional model}

According to the conceptual model, the left side of upflow zone was modeled (Figure 4.3). The simplified Onikobe geothermal system and initial/boundary conditions are illustrated in Figure 4.4. The initial conditions represent a temperature distribution which is linear between $30^{\circ} \mathrm{C}$ at the top of the computational region and $117^{\circ} \mathrm{C}$ at the bottom. The fluid pressure at the top of the computational region is maintained at a constant 21 bars, and the initial pressure distribution with depth ishydrostatic. The right sides of the computing region are considered impermeable and insulated, these conditions represent center of geothermal system. The left side is considered permeable and a constant temperature boundary. At the bottom of the computing region, a uniform upward conductive heat flux is imposed, equal to $0.18 \mathrm{~W} / \mathrm{m}^{2}$. This value is equal to the conductive heat flux associated with the initial temperature gradient $\left(60^{\circ} \mathrm{C} / \mathrm{km}\right)$ acting through the thermal conductivity assumed to prevail throughout the computing volume for the entire calculation $\left(3 \mathrm{~W} / \mathrm{m} \cdot{ }^{\circ} \mathrm{C}\right)$. In addition, at the beginning of the calculation an upward convective source of hot $\left(290^{\circ} \mathrm{C}\right)$ water starts flowing into the region from the bottom of right side at a fixed rate $(20 \mathrm{~kg} / \mathrm{s})$. The $4.5 \mathrm{~km}$ x $1.5 \mathrm{~km}(1 \mathrm{~km}$ perspective $)$ study region is subdivided into 675 grid-blocks $(45 \times 15)$ for computational purposes. All three rock formations are treated as porous media, and rock mineralogy is considered uniform throughout the region for simplicity. The three different formations are distinguished by their porosity and permeability (Table 4.1).

The model was first run under natural conditions for 50000 years to reach a steady-state for fluid and heat flow, and the resulting steady-state temperature distribution is presented in Figure 4.5. Then we simulated reactive chemical transport and water-rock interactions using the steady-state as the initial condition. The non-isothermal fluid flow and reactive geochemical transport was simulated for 10000 years with fluid mass source and then 100 years with production $(X=3300 \mathrm{~m}-3400 \mathrm{~m}, \mathrm{Z}=$ $-1000 \mathrm{~m}--1100 \mathrm{~m}, \mathrm{Q}=72.2 \mathrm{~kg} / \mathrm{s})$ and injection $(X=4000 \mathrm{~m}-4100 \mathrm{~m}, \mathrm{Z}=-300 \mathrm{~m}--400 \mathrm{~m}, \mathrm{Q}=55.5$ $\left.\mathrm{kg} / \mathrm{s}, \mathrm{T}=100^{\circ} \mathrm{C}\right)$. 


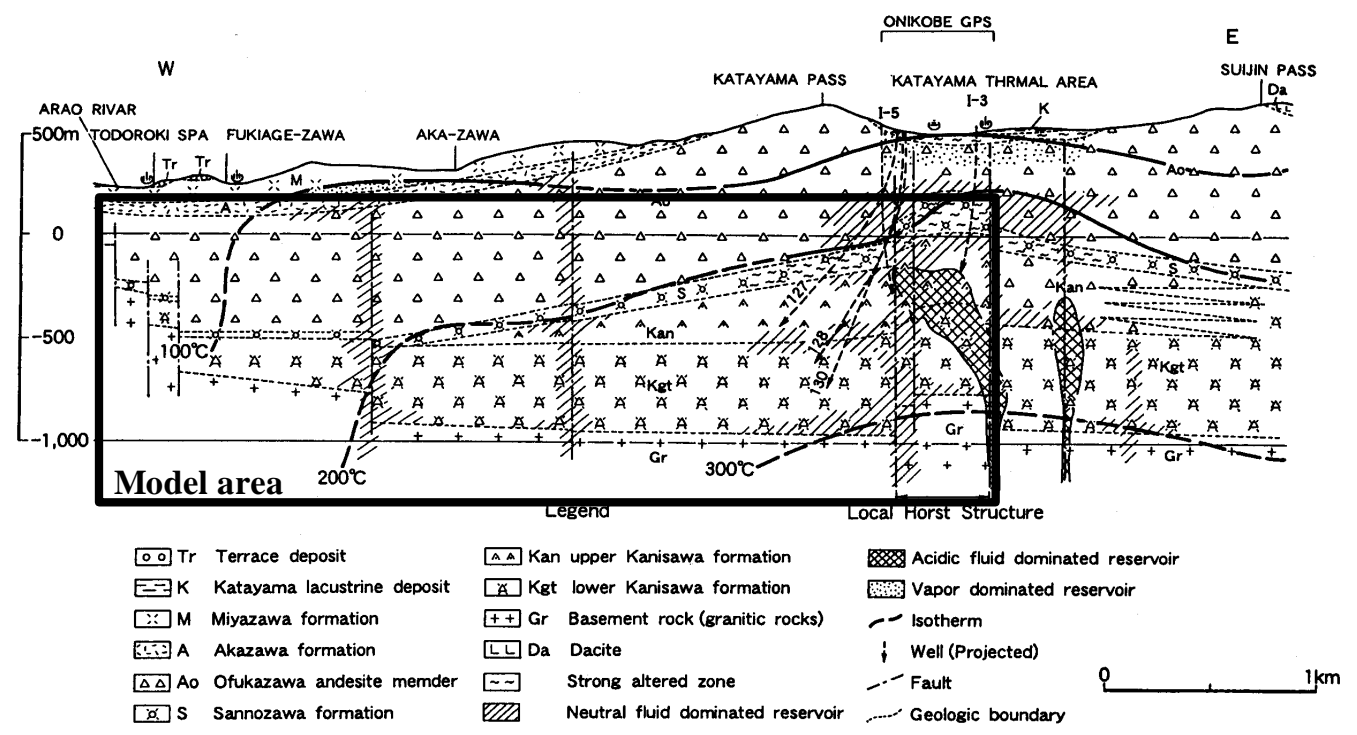

Fig. 4.3 Two-dimensional model area

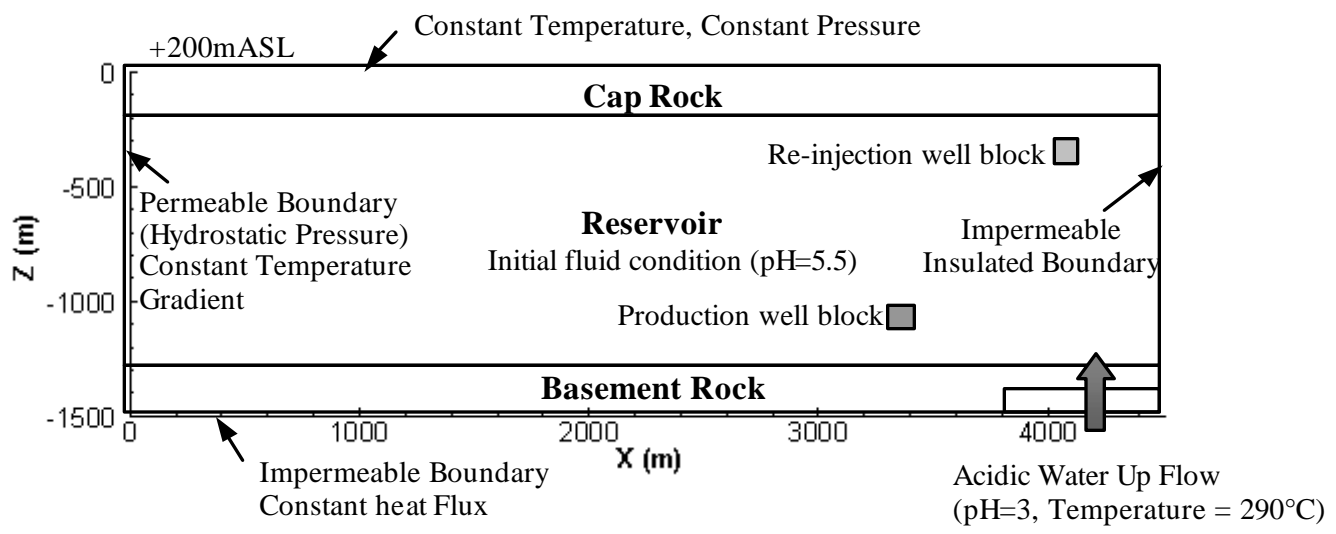

F igure 4.4 Conditions of two-dimensional model

Table 4.1 Distributions of rock properties

\begin{tabular}{lccc}
\hline \multicolumn{1}{c}{ Formation } & Porosity & $\begin{array}{c}\text { Horizontal } \\
\text { Permeability }\end{array}$ & $\begin{array}{c}\text { Vertical } \\
\text { Permeability }\end{array}$ \\
\hline Cap rock & 0.1 & $0.5 \times 10^{-15} \mathrm{~m}^{2}$ & $0.05 \times 10^{-15} \mathrm{~m}^{2}$ \\
Reservoir & 0.1 & $20 \times 10^{-15} \mathrm{~m}^{2}$ & $20 \times 10^{-15} \mathrm{~m}^{2}$ \\
Basement & 0.1 & $0.5 \times 10^{-15} \mathrm{~m}^{2}$ & $0.5 \times 10^{-15} \mathrm{~m}^{2}$ \\
Basement (upflow) & 0.1 & $0.5 \times 10^{-15} \mathrm{~m}^{2}$ & $5 \times 10^{-15} \mathrm{~m}^{2}$ \\
\hline
\end{tabular}




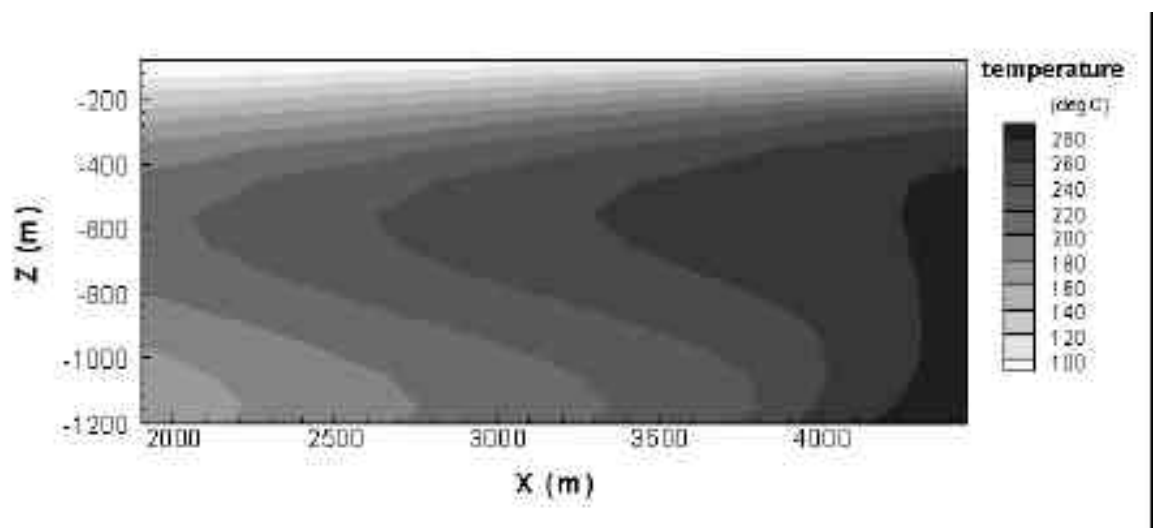

Figure 4.5 Temperature distribution in steady-state condition (50000 years)

\subsection{Geochemical Conditions}

Two types of production fluids occur in the Onikobe geothermal reservoir. The neutral fluid has a $\mathrm{pH}$ of 5.5 under reservoir conditions; it is called neutral in this report because the water at the separator is neutral in the ambient condition. Water from well 134 is selected as representative of initial water and the acidic fluid from well 130 as boundary water. Chemical concentrations of initial and boundary waters are calculated from separated waters (equal to re-injected water) and vapors from well 134 and well 130 using their total enthalpies (Table 4.2). The agreement between enthalpy derived and geothermometer temperatures suggests that there is little excess steam, consistent with inlet vapor fraction values which are less than 0.1 for almost all samples. Aqueous species considered in calculations are listed in Table 4.3.

In order to make the calculation fit for the Onikobe geothermal field, it is important to select the appropriate secondary mineral assemblage that may appear in the TOUGHREACT simulation. Initial mineral abundance and possible secondary minerals considered in the simulations are listed in Table 4.4. Possible secondary minerals were determined from field and experimental observations of water-rock interaction and from equilibrium geochemical model calculations. Figure 4.6 shows the secondary minerals identified from microscope and X-ray diffraction data of drillcores and cuttings. Todaka and Mezaki (1999) employed the batch geochemical code SOLVEQ/CHILLER (Reed, 1982) to analyze the possible secondary minerals at the Onikobe field. Possible secondary minerals (i.e., those allowed to precipitate but which may not necessarily form) were determined from field and experimental observations of water-rock interaction and from equilibrium geochemical model calculations. Calcite and anhydrite dissolution and precipitation were assumed to take place under chemical equilibrium; whereas those of the other minerals were considered under kinetic conditions. A general form of kinetic rate law (Steefel and Lasaga, 1994) is used, 


$$
\mathrm{r}_{\mathrm{m}}=\mathrm{A}_{\mathrm{m}} \mathrm{k}_{\mathrm{m}} \stackrel{?}{?} \stackrel{?}{?} \stackrel{?}{?} \stackrel{?}{?} \frac{\mathrm{Q}_{\mathrm{m}}}{?} \stackrel{?}{?}_{\mathrm{m}}^{?} \stackrel{?}{?} \stackrel{?}{?}^{\mathrm{n}}
$$

where $\mathrm{m}$ is mineral index, $\mathrm{r}_{\mathrm{m}}$ is the dissolution/precipitation rate (positive values indicate dissolution, and negative values precipitation), $A_{m}$ is the specific reactive surface area per $\mathrm{kg} \mathrm{H}_{2} \mathrm{O}, \mathrm{k}_{\mathrm{m}}$ is the rate constant (moles per unit mineral surface area and unit time) which is temperature dependent, $\mathrm{K}_{\mathrm{m}}$ is the equilibrium constant for the mineral-water reaction written for the destruction of one mole of mineral $\mathrm{m}$, and $\mathrm{Q}_{\mathrm{m}}$ is the ion activity product. The parameters ? and $\mathrm{n}$ are positive numbers normally determined by experiment, and are usually, but not always, taken equal to unity (as in the present work). The temperature dependence of the reaction rate constant can be expressed reasonably well via an Arrhenius equation (Steefel and Lasaga, 1994). Since many rate constants are reported at $25^{\circ} \mathrm{C}$, it is convenient to approximate the rate constant dependency as a function of temperature as

$$
\mathrm{k} ? \mathrm{k}_{25} \exp \underset{?}{\stackrel{?}{?} \mathrm{R}} \mathrm{E}_{\mathrm{a}} ? \frac{1}{?} ? \frac{1}{\mathrm{~T}} ? \frac{?}{298.15} ? ?
$$

where $\mathrm{E}_{\mathrm{a}}$ is the activation energy, $\mathrm{k}_{25}$ is the rate constant at $25^{\circ} \mathrm{C}, \mathrm{R}$ is the universal gas constant, and $\mathrm{T}$ is absolute temperature. Parameters $\mathrm{k}_{25}$ and $\mathrm{E}_{\mathrm{a}}$ are taken from Johnson et al. (1998), Hardin (1998) and Tester et al. (1994) or estimated from data therein. The reactive surface areas of minerals used are given in the last column of Table 4.4.

The equilibrium constants were taken from the EQ3/6 V7.2b database (Wolery, 1992) which was derived using SUPCRT92 (Johnson et al., 1992). The equilibrium constant of Mn-rich smectite (Table 4.5) was calculated based on Tardy and Garrels (1974) and Johnson et al. (1992). The chemical composition of Mn-rich smectite (Table 4.6) is that of smectite scale formed by fluid mixing in the production well 128 at the Onikobe geothermal field. 
Table 4.2 Water chemical compositions used for initial and boundary conditions of the reactive chemical transport simulations.

\begin{tabular}{lccc}
\hline Component & $\begin{array}{c}\text { Initial water } \\
\text { (Neutral water) }\end{array}$ & $\begin{array}{c}\text { Boundary water Re-injected water } \\
\text { (Acidic water) } \\
\text { mole/kg }\end{array}$ \\
\hline $\mathrm{H}^{+*}$ & $2.745 \mathrm{E}-06$ & $3.863 \mathrm{E}-04$ & $9.212 \mathrm{E}-04$ \\
$\mathrm{Cl}^{-}$ & $4.442 \mathrm{E}-02$ & $9.909 \mathrm{E}-02$ & $1.442 \mathrm{E}-01$ \\
$\mathrm{SO}_{4}^{-}$ & $6.500 \mathrm{E}-03$ & $1.150 \mathrm{E}-02$ & $1.839 \mathrm{E}-04$ \\
$\mathrm{HCO}_{3}^{-}$ & $1.372 \mathrm{E}-02$ & $1.782 \mathrm{E}-02$ & $1.000 \mathrm{E}-15$ \\
$\mathrm{SiO}_{2}$ & $8.498 \mathrm{E}-03$ & $8.428 \mathrm{E}-03$ & $1.218 \mathrm{E}-02$ \\
$\mathrm{Al}^{+++}$ & $5.656 \mathrm{E}-06$ & $9.577 \mathrm{E}-06$ & $1.384 \mathrm{E}-05$ \\
$\mathrm{Ca}^{++}$ & $3.098 \mathrm{E}-03$ & $1.127 \mathrm{E}-02$ & $1.629 \mathrm{E}-02$ \\
$\mathrm{Mg}^{++}$ & $5.992 \mathrm{E}-06$ & $1.143 \mathrm{E}-03$ & $1.652 \mathrm{E}-03$ \\
$\mathrm{Fe}^{++}$ & $1.491 \mathrm{E}-06$ & $2.214 \mathrm{E}-03$ & $3.199 \mathrm{E}-03$ \\
$\mathrm{~K}^{+}$ & $3.814 \mathrm{E}-03$ & $7.412 \mathrm{E}-03$ & $1.071 \mathrm{E}-02$ \\
$\mathrm{Na}^{+}$ & $3.470 \mathrm{E}-02$ & $6.228 \mathrm{E}-02$ & $8.999 \mathrm{E}-02$ \\
$\mathrm{Mn}^{++}$ & $2.399 \mathrm{E}-06$ & $5.784 \mathrm{E}-05$ & $8.358 \mathrm{E}-05$ \\
$\mathrm{Zn}^{++}$ & $1.061 \mathrm{E}-07$ & $3.376 \mathrm{E}-05$ & $4.878 \mathrm{E}-05$ \\
$\mathrm{~Pb}^{++}$ & $1.000 \mathrm{E}-12$ & $5.899 \mathrm{E}-06$ & $8.524 \mathrm{E}-06$ \\
$\mathrm{O}_{2}$ & $1.724 \mathrm{E}-40$ & $2.344 \mathrm{E}-40$ & $2.344 \mathrm{E}-40$ \\
$t^{+2 m p e r a t u r e}\left({ }^{\circ} \mathrm{C}\right.$, & 250 & 254 & 100 \\
$w^{*}$ & 134 & 130 & 130 \\
\hline$*:$ activity & & &
\end{tabular}


Table 4.3 Aqueous species considered in simulations at the Onikobe field

\begin{tabular}{|c|c|c|c|}
\hline Primary species & Secondary & pecies & \\
\hline $\mathrm{H}_{2} \mathrm{O}$ & $\mathrm{AlOH}^{2+}$ & $\mathrm{FeOH}^{+}$ & $\mathrm{HSO}_{4}^{-}$ \\
\hline $\mathrm{H}^{+}$ & $\mathrm{Al}(\mathrm{OH})_{2}^{+}$ & $\mathrm{Fe}(\mathrm{OH})_{2}(\mathrm{aq})$ & $\mathrm{H}_{3} \mathrm{SiO}_{4}^{-}$ \\
\hline $\mathrm{Ca}^{2+}$ & $\mathrm{Al}(\mathrm{OH})_{4}^{-}$ & $\mathrm{Fe}(\mathrm{OH})_{3}(\mathrm{aq})$ & $\mathrm{HS}^{-}$ \\
\hline $\mathrm{Mg}^{2+}$ & $\mathrm{CaCl}^{+}$ & $\mathrm{H}_{2}(\mathrm{aq})$ & $\mathrm{MnCO}_{3}(\mathrm{aq})$ \\
\hline $\mathrm{Na}^{+}$ & $\mathrm{CaCl}_{2}(\mathrm{aq})$ & $\mathrm{KCl}(\mathrm{aq})$ & $\mathrm{MnOH}^{+}$ \\
\hline $\mathrm{K}^{+}$ & $\mathrm{CaCO}_{3}(\mathrm{aq})$ & $\mathrm{KSO}_{4}^{-}$ & $\mathrm{ZnCl}^{+}$ \\
\hline $\mathrm{Fe}^{2+}$ & $\mathrm{CaHCO}_{3}^{+}$ & $\mathrm{MgCl}^{+}$ & $\mathrm{ZnCl}_{2}(\mathrm{aq})$ \\
\hline $\mathrm{Cl}^{-}$ & $\mathrm{CaOH}^{+}$ & $\mathrm{MgHCO}_{3}^{+}$ & $\mathrm{ZnCl}_{3}^{-}$ \\
\hline $\mathrm{SiO}_{2}(\mathrm{aq})$ & $\mathrm{CaSO}_{4}(\mathrm{aq})$ & $\mathrm{MgOH}^{+}$ & $\mathrm{ZnCl}_{4}{ }^{2-}$ \\
\hline $\mathrm{HCO}_{3}^{-}$ & $\mathrm{CH}_{4}(\mathrm{aq})$ & $\mathrm{NaCl}(\mathrm{aq})$ & $\mathrm{ZnOH}^{+}$ \\
\hline $\mathrm{SO}_{4}^{2-}$ & $\mathrm{HCl}(\mathrm{aq})$ & $\mathrm{NaCO}_{3}^{-}$ & $\mathrm{PbCl}^{+}$ \\
\hline $\mathrm{Al}^{3+}$ & $\mathrm{CO}_{3}^{2-}$ & $\mathrm{NaHCO}_{3}(\mathrm{aq})$ & $\mathrm{PbCl}_{2}(\mathrm{aq})$ \\
\hline $\mathrm{O}_{2}(\mathrm{aq})$ & $\mathrm{CO}_{2}(\mathrm{aq})$ & $\mathrm{NaOH}(\mathrm{aq})$ & $\mathrm{PbCl}_{3}^{-}$ \\
\hline $\mathrm{Mn}^{2+}$ & $\mathrm{FeCl}^{+}$ & $\mathrm{NaSO}_{4}^{-}$ & $\mathrm{PbCl}_{4}^{2-}$ \\
\hline $\mathrm{Zn}^{2+}$ & $\mathrm{FeCl}_{2}(\mathrm{aq})$ & $\mathrm{OH}$ & $\mathrm{PbOH}^{+}$ \\
\hline $\mathrm{Pb}^{2+}$ & $\mathrm{FeCl}_{4}^{2-}$ & $\mathrm{H}_{2} \mathrm{~S}(\mathrm{aq})$ & \\
\hline
\end{tabular}

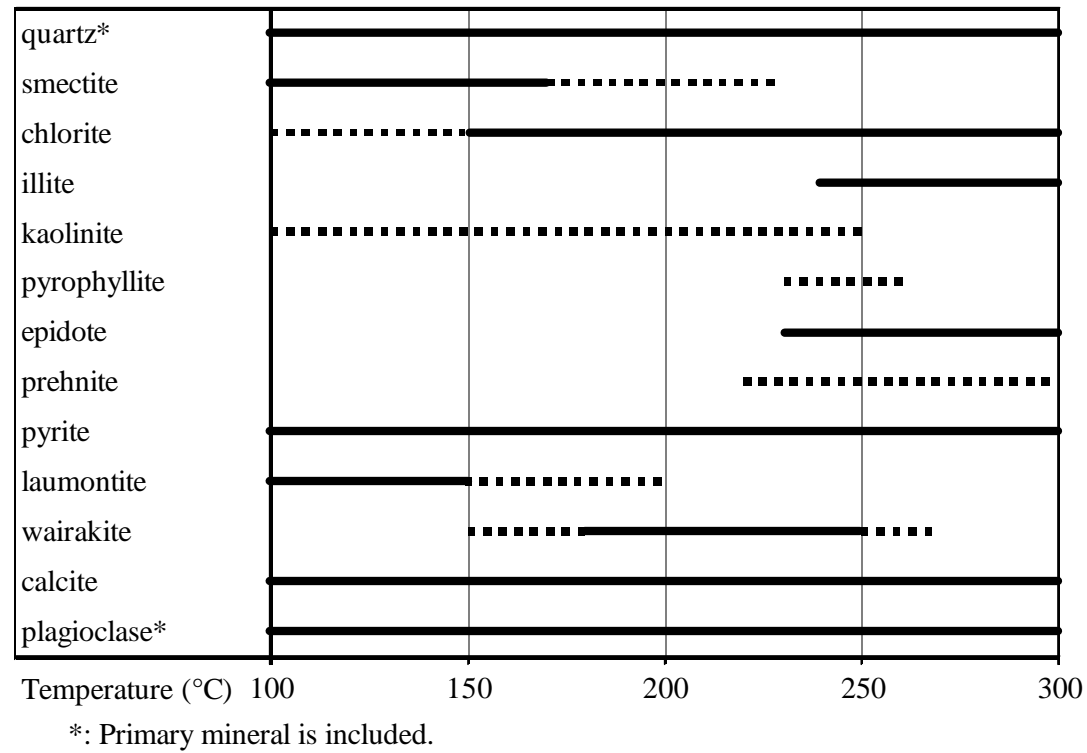

Figure 4.6 Alteration mineral assemblage in the Onikobe geothermal wells as a function of temperature 
Table 4.4 List of initial mineral volume fractions, possible secondary mineral phases, and their kinetic properties used in the simulation $\left(\mathrm{k}_{25}\right.$ is the kinetic rate constant at $25^{\circ} \mathrm{C}$, and $\mathrm{E}_{\mathrm{a}}$ activation energy)

\begin{tabular}{|c|c|c|c|c|c|}
\hline Mineral & Composition & Vol. Frac & $\begin{array}{c}\mathrm{k}_{25} \\
\text { moles } /\left(\mathrm{m}^{2} \mathrm{~S}\right)\end{array}$ & $\begin{array}{c}\mathrm{E}_{\mathrm{a}} \\
\mathrm{kJ} / \mathrm{mole}\end{array}$ & $\begin{array}{c}\begin{array}{c}\text { Surface area } \\
\mathrm{cm}^{2} / \mathrm{g}\end{array} \\
\end{array}$ \\
\hline \multicolumn{6}{|l|}{ Primary: } \\
\hline quartz & $\mathrm{SiO}_{2}$ & 0.1477 & $1.04 \times 10^{-14}$ & 87.70 & 14.77 \\
\hline K-feldspar & $\mathrm{KAlSi}_{3} \mathrm{O}_{8}$ & 0.0495 & $1.78 \times 10^{-12}$ & 36.00 & 4.95 \\
\hline albite & $\mathrm{NaAlSi}_{3} \mathrm{O}_{8}$ & 0.2232 & $7.08 \times 10^{-13}$ & 54.40 & 22.32 \\
\hline anorthite & $\mathrm{CaAl}_{2} \mathrm{Si}_{2} \mathrm{O}_{8}$ & 0.3145 & $1.50 \times 10^{-14}$ & 18.40 & 0.01 \\
\hline diopside & $\mathrm{CaMgSi}_{2} \mathrm{O}_{6}$ & 0.0149 & $1.00 \times 10^{-13}$ & 54.40 & 1.49 \\
\hline hedenbergite & $\mathrm{CaFeSi}_{2} \mathrm{O}_{6}$ & 0.0098 & $1.00 \times 10^{-13}$ & 54.40 & 0.98 \\
\hline enstatite & $\mathrm{MgSiO}_{3}$ & 0.0736 & $1.00 \times 10^{-13}$ & 54.40 & 7.26 \\
\hline ferrosilite & $\mathrm{FeSiO}_{3}$ & 0.0493 & $1.00 \times 10^{-13}$ & 54.40 & 4.93 \\
\hline magnetite & $\mathrm{Fe}_{3} \mathrm{O}_{4}$ & 0.0176 & $1.00 \times 10^{-13}$ & 54.40 & 1.76 \\
\hline porosity & & 0.1 & & & \\
\hline total & & 1.0 & & & \\
\hline \multicolumn{6}{|l|}{ Secondary: } \\
\hline clinochlore & $\mathrm{Mg}_{5} \mathrm{Al}_{2} \mathrm{Si}_{3} \mathrm{O}_{10}(\mathrm{OH})_{8}$ & 0.0 & $1.00 \times 10^{-14}$ & 62.76 & 100 \\
\hline daphnite & $\mathrm{Fe}_{5} \mathrm{Al}_{2} \mathrm{Si}_{3} \mathrm{O}_{10}(\mathrm{OH})_{8}$ & 0.0 & $1.00 \times 10^{-14}$ & 62.76 & 100 \\
\hline illite & $\mathrm{K}_{0.6} \mathrm{Mg}_{0.25} \mathrm{Al}_{1.8}\left(\mathrm{Al}_{0.5} \mathrm{Si}_{3.5} \mathrm{O}_{10}(\mathrm{OH})_{2}\right.$ & 0.0 & $1.00 \times 10^{-14}$ & 58.62 & 100 \\
\hline kaolinite & $\mathrm{Al}_{2} \mathrm{Si}_{2} \mathrm{O}_{5}(\mathrm{OH})_{4}$ & 0.0 & $1.00 \times 10^{-14}$ & 71.00 & 100 \\
\hline pyrophyllite & $\mathrm{Al}_{2} \mathrm{Si}_{4} \mathrm{O}_{10}(\mathrm{OH})_{2}$ & 0.0 & $1.00 \times 10^{-14}$ & 71.00 & 100 \\
\hline laumontite & $\mathrm{CaAl}_{2} \mathrm{Si}_{4} \mathrm{O}_{12} 4 \mathrm{H}_{2} \mathrm{O}$ & 0.0 & $1.00 \times 10^{-13}$ & 54.40 & 10 \\
\hline wairakite & $\mathrm{CaAl}_{2} \mathrm{Si}_{4} \mathrm{O}_{12} 2 \mathrm{H}_{2} \mathrm{O}$ & 0.0 & $1.00 \times 10^{-13}$ & 54.40 & 10 \\
\hline prehnite & $\mathrm{Ca}_{2} \mathrm{Al}_{2} \mathrm{Si}_{3} \mathrm{O}_{10}(\mathrm{OH})_{2}$ & 0.0 & $1.00 \times 10^{-13}$ & 54.40 & 10 \\
\hline clinozoisite & $\mathrm{Ca}_{2} \mathrm{Al}_{3} \mathrm{Si}_{3} \mathrm{O}_{12}(\mathrm{OH})$ & 0.0 & $1.00 \times 10^{-13}$ & 54.40 & 10 \\
\hline epidote & $\mathrm{Ca}_{2} \mathrm{Fe}_{3} \mathrm{Si}_{3} \mathrm{O}_{12}(\mathrm{OH})$ & 0.0 & $1.00 \times 10^{-13}$ & 54.40 & 10 \\
\hline Mn-rich smectite & $\left(\mathrm{Ca}_{0.17} \mathrm{Na}_{0.01} \mathrm{~K}_{0.01}\right)\left(\mathrm{Al}_{0.18} \mathrm{Mg}_{1.74} \mathrm{Mn}_{0.85} \mathrm{Fe}_{0.03}\right)\left(\mathrm{Si}_{3.87} \mathrm{Al}_{0.13}\right) \mathrm{O}_{10}(\mathrm{OH})_{2}$ & 0.0 & $1.00 \times 10^{-14}$ & 58.62 & 100 \\
\hline pyrite & $\mathrm{FeS}_{2}$ & 0.0 & $1.00 \times 10^{-13}$ & 0.00 & 0.001 \\
\hline sphalerite & $\mathrm{ZnS}$ & 0.0 & $1.00 \times 10^{-13}$ & 0.00 & 0.001 \\
\hline galena & $\mathrm{PbS}$ & 0.0 & $1.00 \times 10^{-13}$ & 0.00 & 0.001 \\
\hline calcite & $\mathrm{CaCO}_{3}$ & 0.0 & at equilibrium & & \\
\hline anhydrite & $\mathrm{CaSO}_{4}$ & 0.0 & at equilibrium & & \\
\hline
\end{tabular}

Table 4.5 Equilibrium constant of Mn-rich smectite scale formed in the Onikobe production well. It was calculated based on Tardy and Garrels (1974) and Johnson et al. (1992).

\begin{tabular}{lcccccccc}
\hline Temperature $\left({ }^{\circ} \mathrm{C}\right)$ & 0 & 25 & 60 & 100 & 150 & 200 & 250 & 300 \\
$\log \mathrm{K}$ & 22.928 & 20.835 & 17.706 & 14.529 & 11.347 & 8.799 & 6.639 & 4.634 \\
\hline
\end{tabular}

Table 4.6 Chemical composition of Mn-rich smectite scale in the Onikobe production well.

\begin{tabular}{rllllllllll}
\hline $\mathrm{SiO}_{2}$ & $\mathrm{Al}_{2} \mathrm{O}_{3}$ & $\mathrm{TiO}_{2}$ & $\mathrm{MgO}$ & $\mathrm{MnO}$ & $\mathrm{FeO} *$ & $\mathrm{ZnO}$ & $\mathrm{CaO}$ & $\mathrm{Na}_{2} \mathrm{O}$ & $\mathrm{K}_{2} \mathrm{O}$ & Total \\
52.92 & 3.54 & 0.02 & 15.98 & 13.74 & 0.55 & 0.07 & 2.15 & 0.10 & 0.08 & 89.15 \\
\hline \multicolumn{10}{c}{ *: total $\mathrm{FeO}$} & \\
\hline
\end{tabular}




\section{Results and Discussion}

\subsection{One-dimensional model}

(1) Non-flow model

Non-flow (batch) simulation was performed to study mineral assemblages and uncertain parameters such as equilibrium and kinetic conditions. Possible secondary minerals and reactive surface areas were determined by trial-and-error simulation as shown in Figure 2.1. The non-flow simulation results in small changes in chemical concentrations and precipitation/dissolution rates (mineral volume fractions) between initial and steady-state conditions.

Steady-state conditions are reached after 10,000 years. The pH increases slightly with time and then remains the same at 5.8 at $250^{\circ} \mathrm{C}$ after 10,000 years (Figure 5.1). Most components except $\mathrm{Mg}$, $\mathrm{Fe}, \mathrm{Mn}$ and $\mathrm{Al}$ have almost constant concentrations. Concentrations of $\mathrm{Mg}, \mathrm{Fe}, \mathrm{Mn}$ and $\mathrm{Al}$ continue to change slightly before 10,000 years and then remain constant. The rates of mineral dissolution and precipitation remain also constant after 10,000 years (Figure 5.2). Consequently, there is little $\mathrm{pH}$ change from the initial condition. Mineral precipitation and dissolution in this simulation were consistent with the field data.

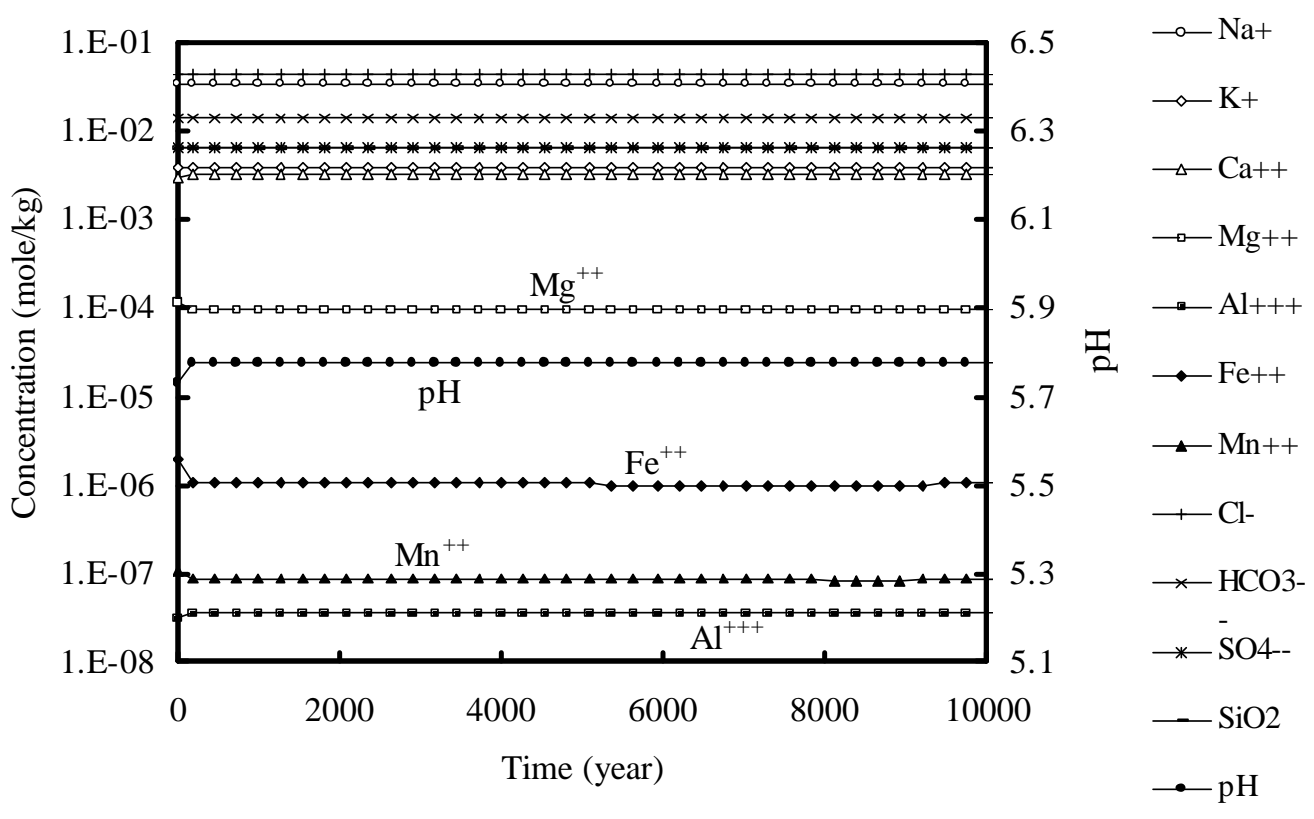

Figure 5.1 Changes in $\mathrm{pH}$ and aqueous concentrations with time in non-flow model at $250^{\circ} \mathrm{C}$ (center block) 


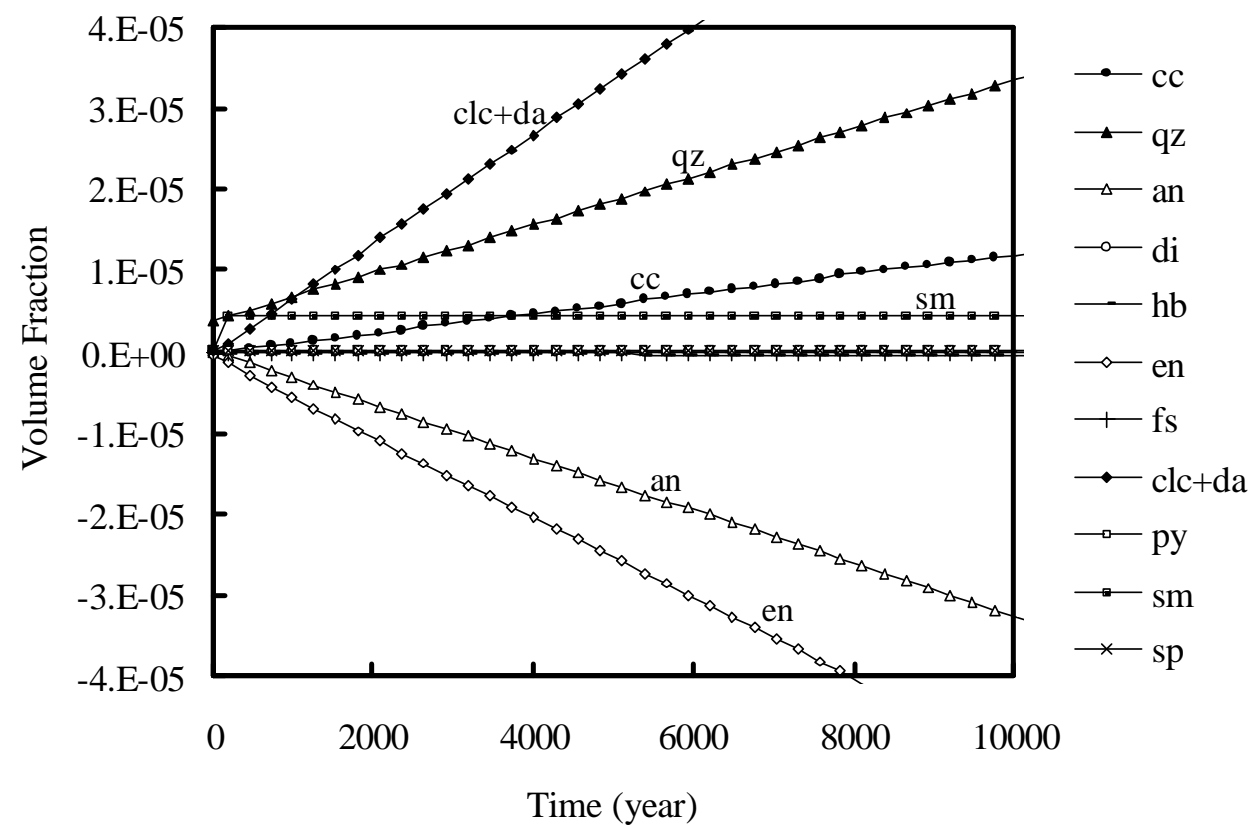

Figure 5.2 Changes in mineral volume fractions with time in non-flow model at $250^{\circ} \mathrm{C}$ (center block). cc: calcite, qz: quartz, an: anorthite, di: diopside, hb: hedenbergite, en: enstatite, fs: ferrosilite, clc: clinochlore, py: pyrite, sm: Mn-rich smectite, sp: sphalerite

\section{(2) Isothermal flow model}

Using the parameter values determined in the non-flow simulation, the flow model was used to test precipitation and dissolution near the mixing region between acidic and neutral fluids. Concentration change of conservative chloride indicates the mixing front. The mixing front in our simulations can be seen easily due to the big difference between chloride concentrations of acidic fluid $(0.099 \mathrm{~mole} / \mathrm{kg})$ and neutral fluid $(0.044 \mathrm{~mole} / \mathrm{kg})$ as shown in Figures 5.3-5.5. In the isothermal flow models $\left(270,250\right.$ and $\left.230^{\circ} \mathrm{C}\right)$, the behavior of total concentration of each element is similar to that of chloride concentration.

Various minerals precipitate or dissolve near the mixing front. Mn-rich smectite precipitates near the mixing front, and then dissolves to disappear in the acidic flow zone at temperatures of 270 and $250^{\circ} \mathrm{C}$ (Figures 5.3 and 5.4). The precipitation peak of Mn-rich smectite moves downstream with time. The peak is consistent with the mixing front. The behavior of mineral precipitation and dissolution at $230^{\circ} \mathrm{C}$ is somewhat different from that at 250 and $270^{\circ} \mathrm{C}$. At $230^{\circ} \mathrm{C}$, a small amount of Mn-rich smectite dissolves by acidic fluid displaced with time (Figure 5.5). It is not clear why the Mn-rich smectite precipitation may occur in acidic fluid zone. This may be due to uncertain parameters.

Calcite precipitates in neutral fluid zone at $230^{\circ} \mathrm{C}$ and dissolves just in front of acidic fluid. 
Precipitation of pyrite, sphalerite and galena occurs in the acidic fluid zone and decreases downstream. Precipitation of these sulfides increases with temperature decreasing. Sulfide precipitation is not related to the mixing front in these isothermal flow simulations.

(3) Non-isothermal flow model

The chloride concentration curve in the non-isothermal flow model moves downstream with little change over time (Figure 5.6). The other concentration curves gradually change as they move downstream. The $\mathrm{SiO}_{2}$ (aq) profile arises from temperature dependence of quartz solubility. The change of $\mathrm{pH}$ due to the movement of the mixing front gradually diminishes with time, compared with that of chloride.

Mn-rich smectite precipitates near the mixing front, and then dissolves by acidic water displaced with time due to the $\mathrm{pH}$ decrease. The movement of the Mn-rich smectite peak (Figure 5.7) is similar to that of $\mathrm{pH}$, and lags behind that of $\mathrm{Cl}$. At the lower temperature, the peak is much higher. Precipitation of pyrite and sphalerite occurs near the mixing front, and their precipitation peaks move with the mixing front. Mn-rich smectite scale in the Onikobe production well also coexists with sphalerite and galena (Ajima et al., 1998). The mineral assemblage of the scale is the same as that found in this simulation. It is likely that this smectite will precipitate by fluid mixing in the Onikobe reservoir. In addition, calcite precipitation is predominant in lower temperature because the $\mathrm{pH}$ is not low. 
(a) 50 years
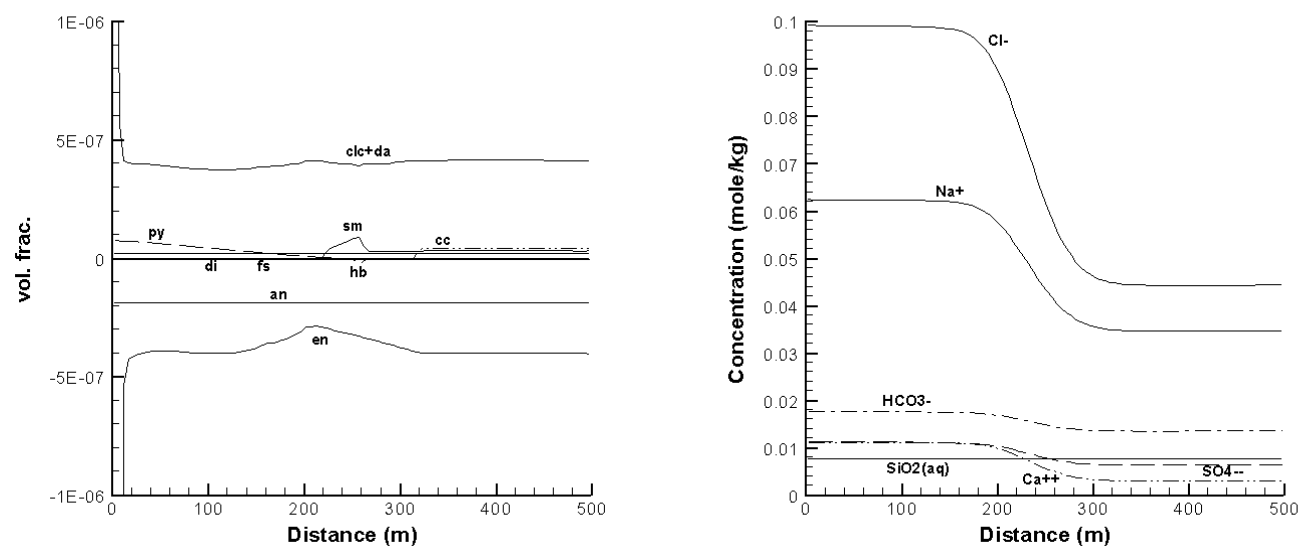

(b) 75 years
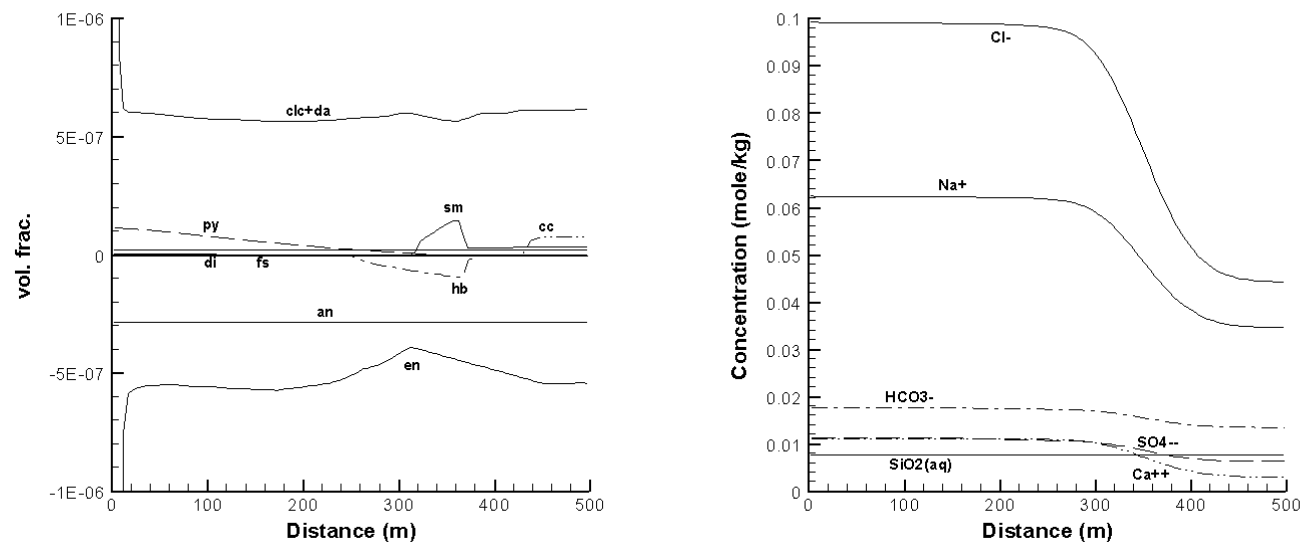

(c) 100 years
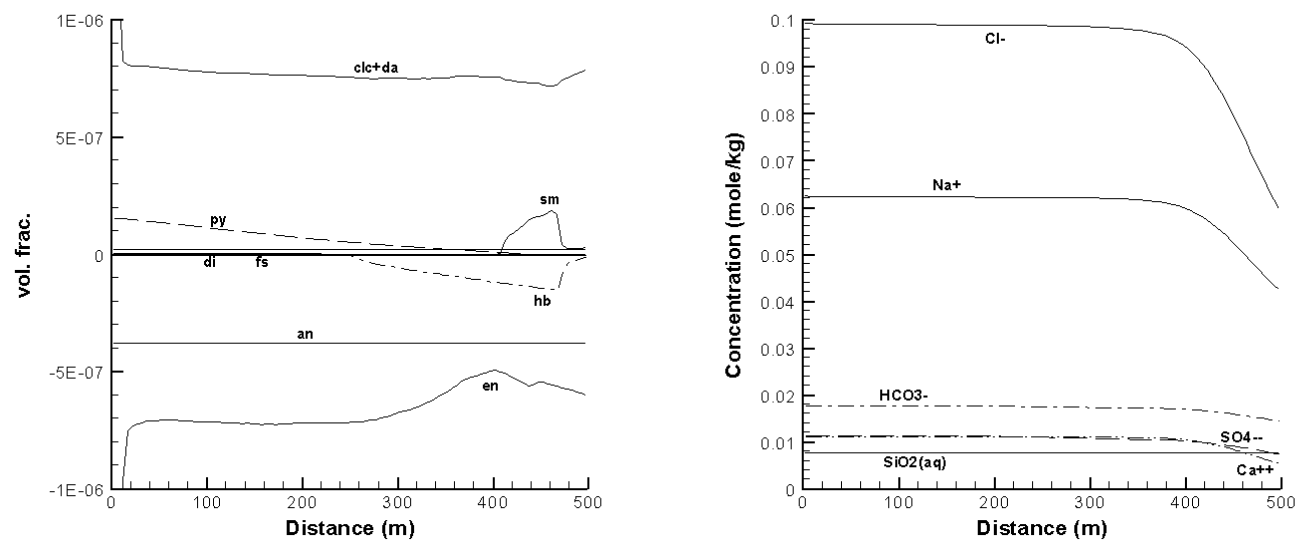

Figure 5.3 One-dimensional isothermal flow model after (a) 50, (b) 75 and (c) 100 years at $270^{\circ} \mathrm{C}$. Abbreviations are as in Figure 4.2. 
(a) 50 years
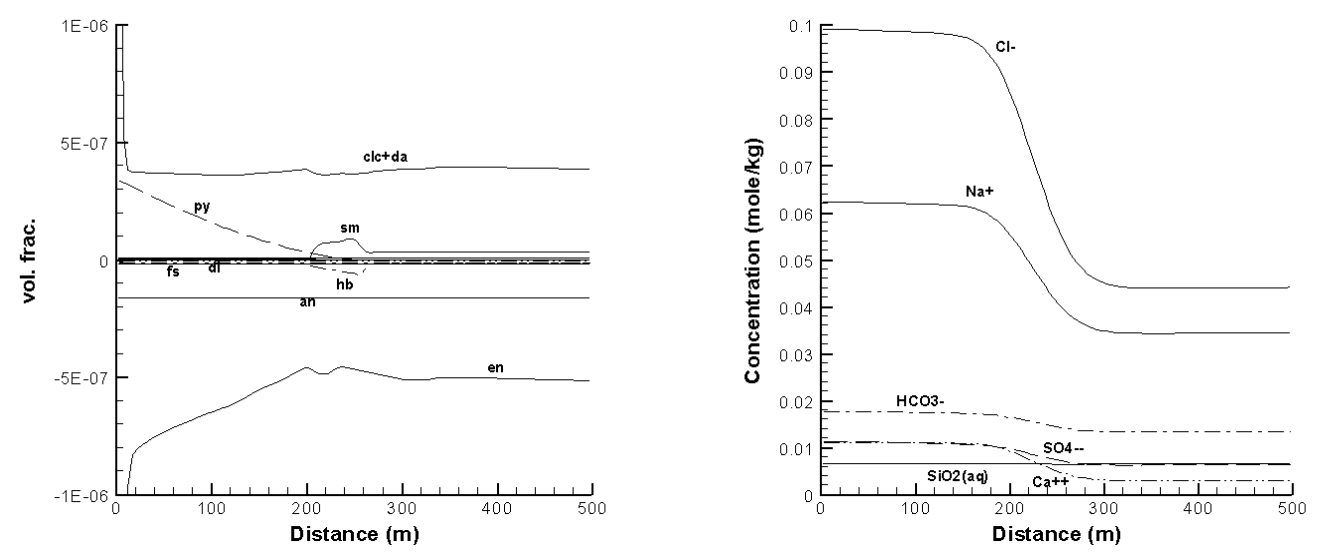

(b) 75 years
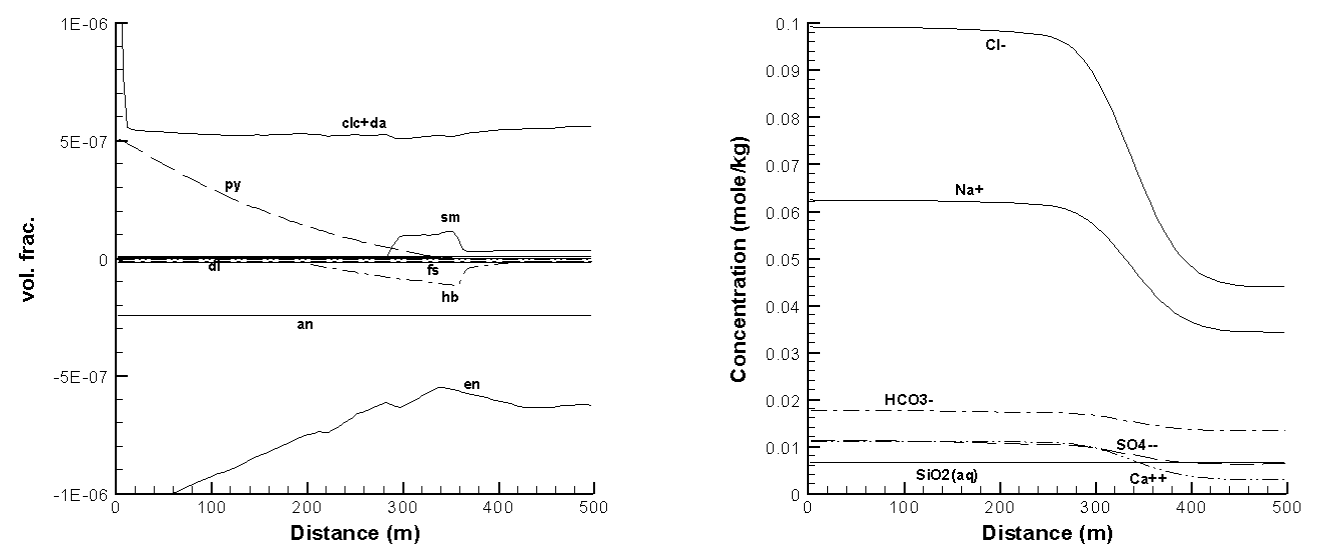

(c) 100 years
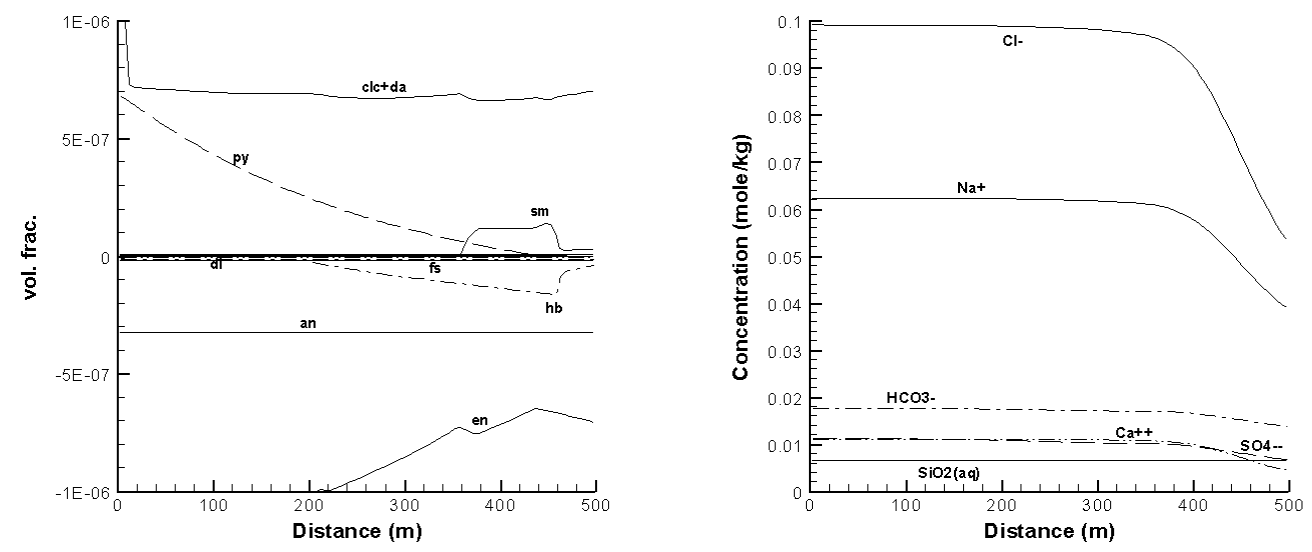

Figure 5.4 One-dimensional isothermal flow model after (a) 50, (b) 75 and (c) 100 years at $250^{\circ} \mathrm{C}$. Abbreviations are as in Figure 4.2. 
(a) 50 years
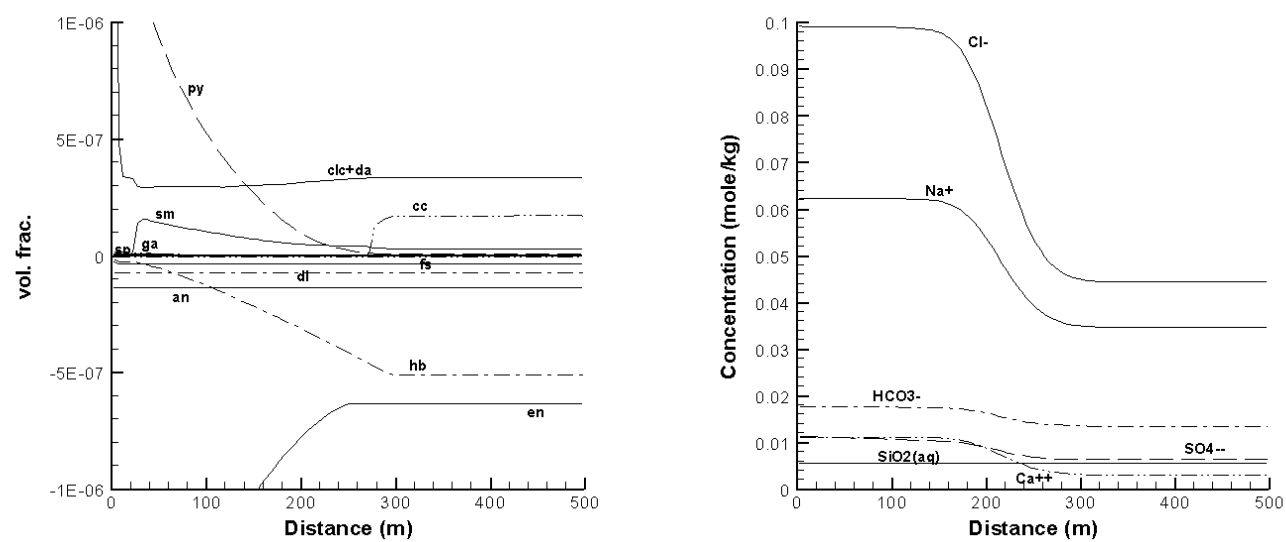

(b) 75 years
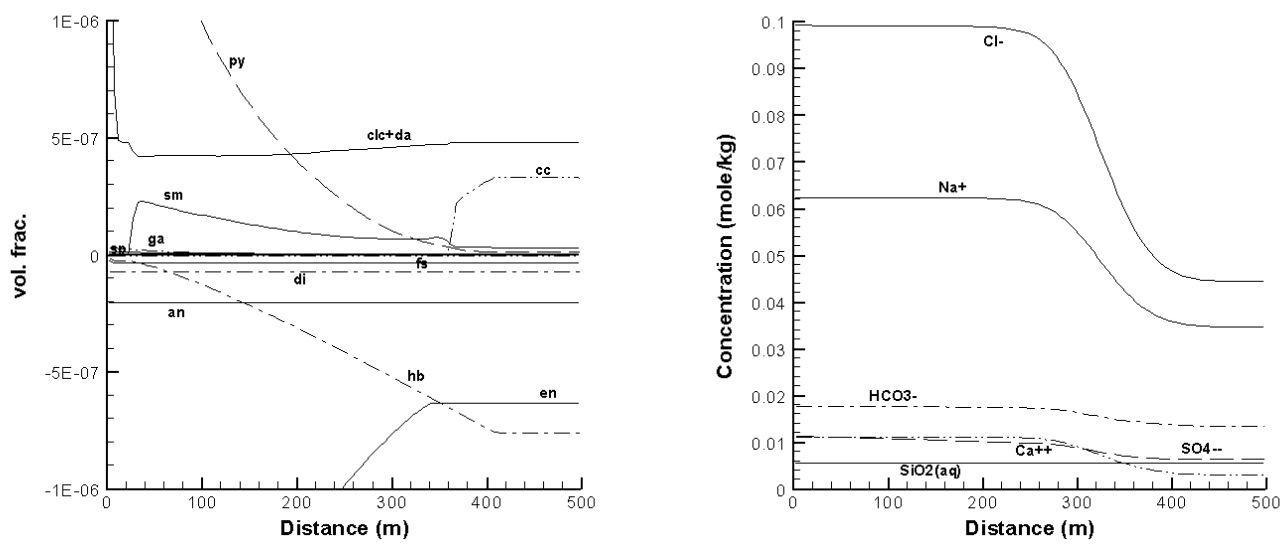

(c) 100 years
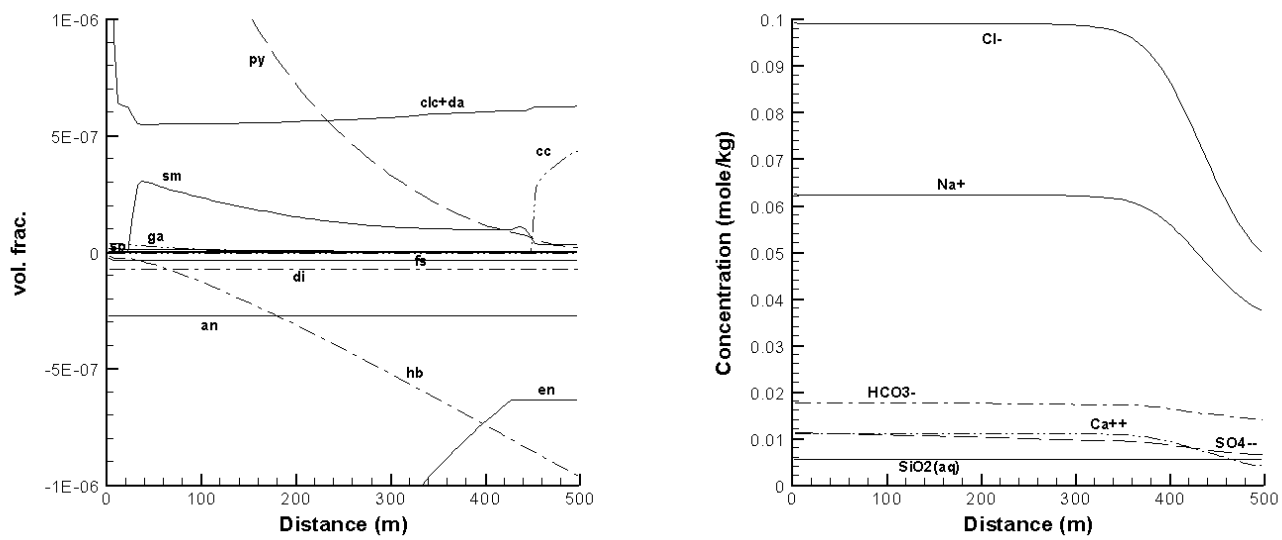

Figure 5.5 One-dimensional isothermal flow model after (a) 50, (b) 75 and (c) 100 years at $230^{\circ} \mathrm{C}$. Abbreviations are as in Figure 4.2. 

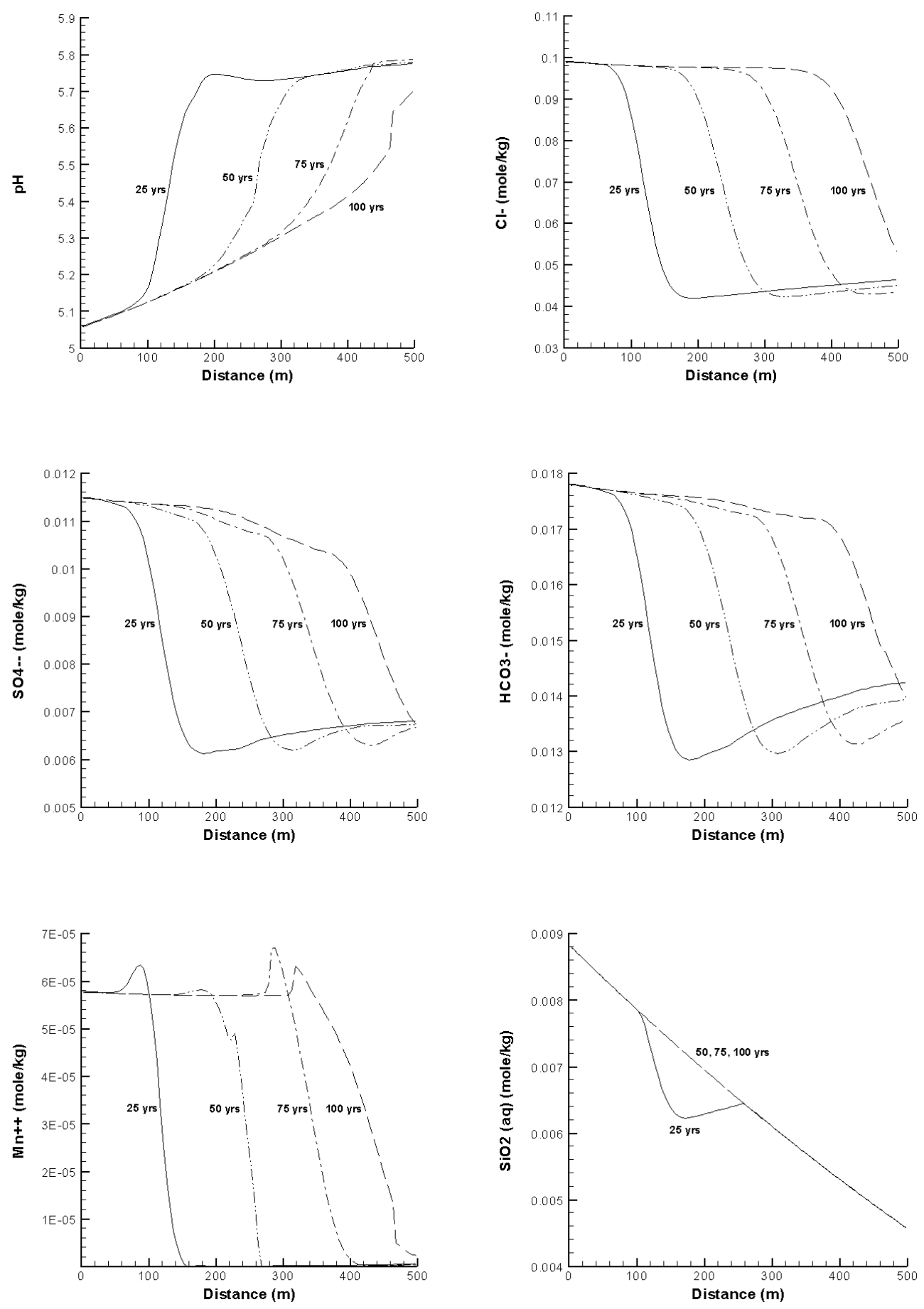

Figure 5.6 One-dimensional non-isothermal flow model from 290 to $210^{\circ} \mathrm{C}$. 

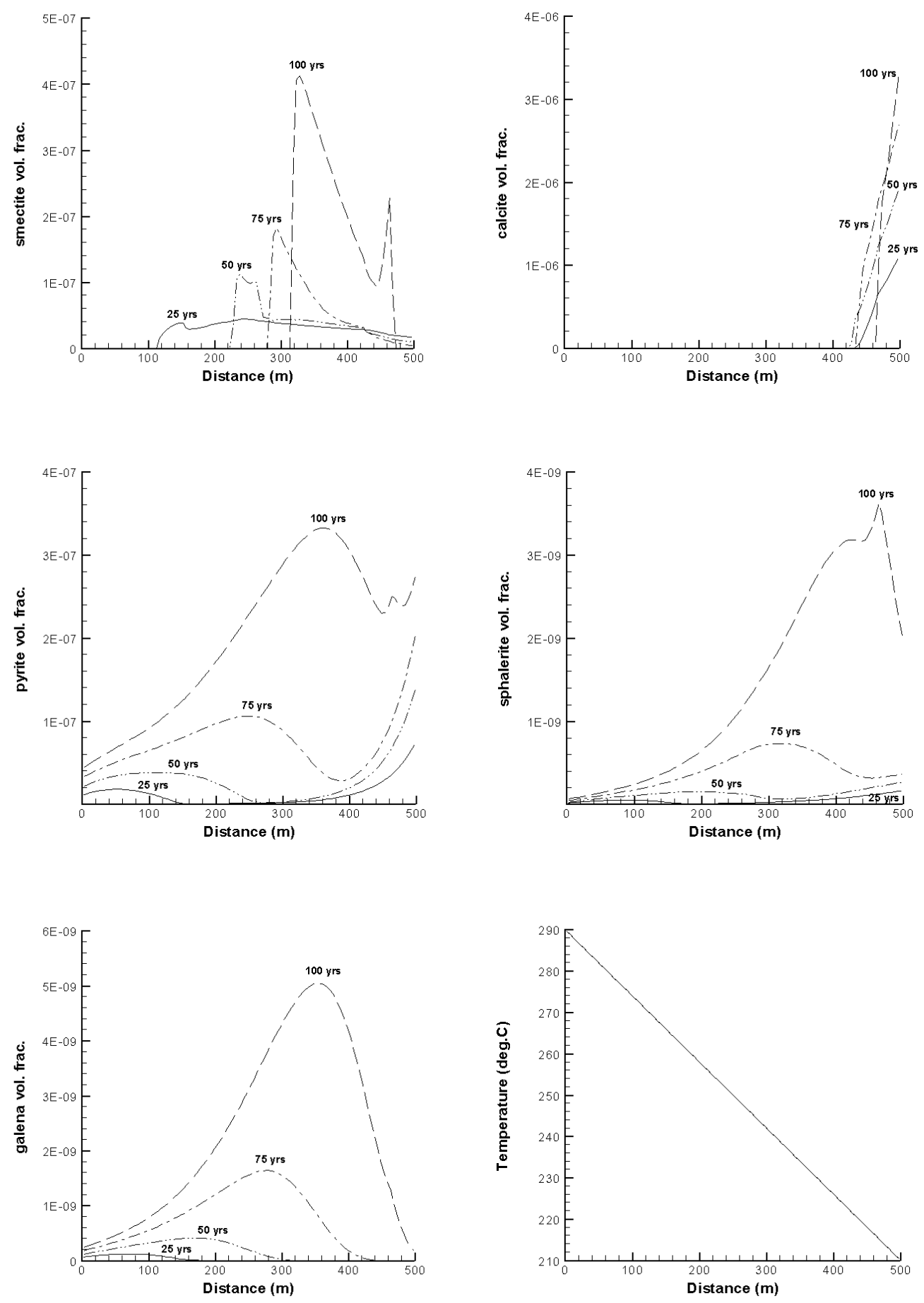

Figure 5.7 One-dimensional non-isothermal flow model from 290 to $210^{\circ} \mathrm{C}$. 


\subsection{Two-dimensional model}

(1) Natural state simulation

Two-dimensional simulations were carried out using the same parameters as in the one-dimensional models. It is difficult to simulate the whole reservoir because the Onikobe subsurface temperature has a wide range (maximum temperature: $313^{\circ} \mathrm{C}$ ). The parameters were adjusted in reservoir temperature (around $250^{\circ} \mathrm{C}$ ), so that the limited area from 230 to $270^{\circ} \mathrm{C}(\mathrm{X}=$ $2000 \mathrm{~m}-4500 \mathrm{~m}, \mathrm{Z}=-100 \mathrm{~m}--1200 \mathrm{~m}$ ) is shown in the contour plots of concentrations and mineral volume fractions.

Quartz, pyrite and calcite clearly precipitate in the shallow zone (cap rock) due to changes in temperature and $\mathrm{pH}$, and porosity and permeability also decrease to develop cap rock. This is a reasonable result because mineral solubility generally decreases with decreasing temperature. Calcite solubility, however, increases with decreasing temperature. Carbonate $\left(\mathrm{CO}_{3}{ }^{2-}\right)$ activity related to calcite depends on the water $\mathrm{pH}$ (acidic water has small carbonate concentration) and the shallow neutral fluid indicates higher activity than the deep acidic fluid. Calcite precipitation in low temperature can be seen also in the one-dimensional flow simulation.

The most predominant precipitation of Mn-rich smectite occurs near mass source where acidic fluid flowing up from greater depth mixes with the neutral fluid flowing laterally. Mn-rich smectite would continue to precipitate there while the acidic fluid (mass source) supplies and mixes with the neutral fluid for the entire simulation time. The other smectite region is located below the region of quartz, pyrite and calcite precipitated in the shallow zone (cap rock). Precipitation of Mn-rich smectite is obviously located above the mushroom shape of acidic fluid with $\mathrm{pH}<5.25$. Little smectite, however, precipitates in the region which is consistent with the result of one-dimensional simulation: i.e. Mn-rich smectite precipitates near the mixing front and then dissolves in the acidic flow zone over $250^{\circ} \mathrm{C}$, but it does not soon dissolve by the acidic water below $250^{\circ} \mathrm{C}$.

Precipitation of sphalerite and galena occurs in a similar region as Mn-rich smectite precipitation. Mn-rich smectite as well as sphalerite and galena forms by mixing of acidic and neutral fluids in the one-dimensional simulation. Mn-rich smectite scale in the Onikobe production well also coexists with sphalerite and galena (Ajima et al., 1998). Mineral assemblage of the scale is the same as that of this simulation. This smectite is likely to precipitate by fluid mixing in the reservoir.

Considering porosity and permeability of rock, the most important mineralization are not only hydrothermal metasomatism (chlorite, illite, kaolinite, epidote etc. are formed by replacement of primary minerals in rocks) but mineral deposition (quartz, calcite, anhydrite precipitate from geothermal fluid in fractures). Quartz, calcite and pyrite are formed by both chemical reactions. Mn-rich smectite is actually confirmed to precipitate at a depth where neutral fluid is encountered by acidic fluid rising from deep feed zone in the Onikobe production wells (Ajima et al., 1998). It is assumed that this smectite is not formed by replacement of primary minerals but that it precipitates by mixing of two different types of fluids in open fractures. The decrease of porosity and permeability 
due to precipitation of Mn-rich smectite is small compared with that of quartz, calcite and pyrite. However, it is likely to form an impermeable barrier between regions with acidic and neutral fluids over geologic time.

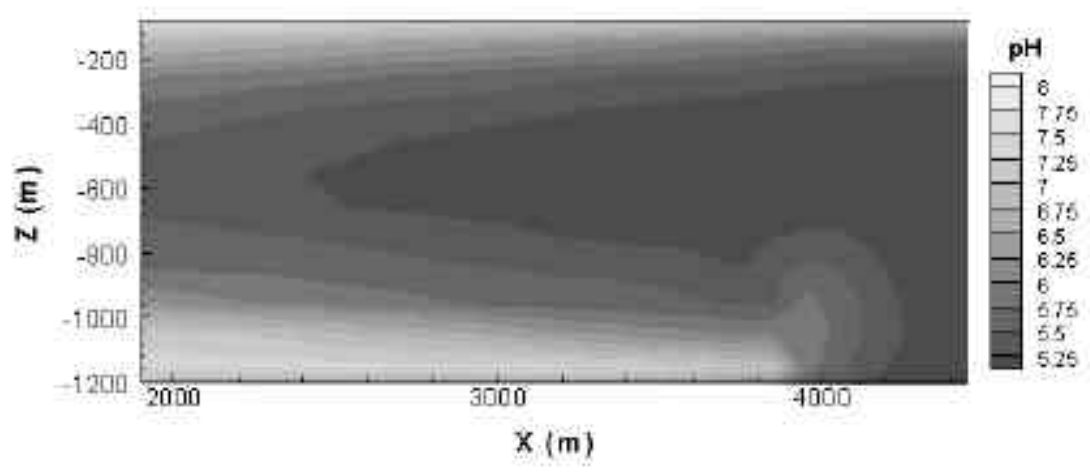

Figure 5.8 Contour plot of water $\mathrm{pH}$ obtained from two-dimensional simulation (10000 years)

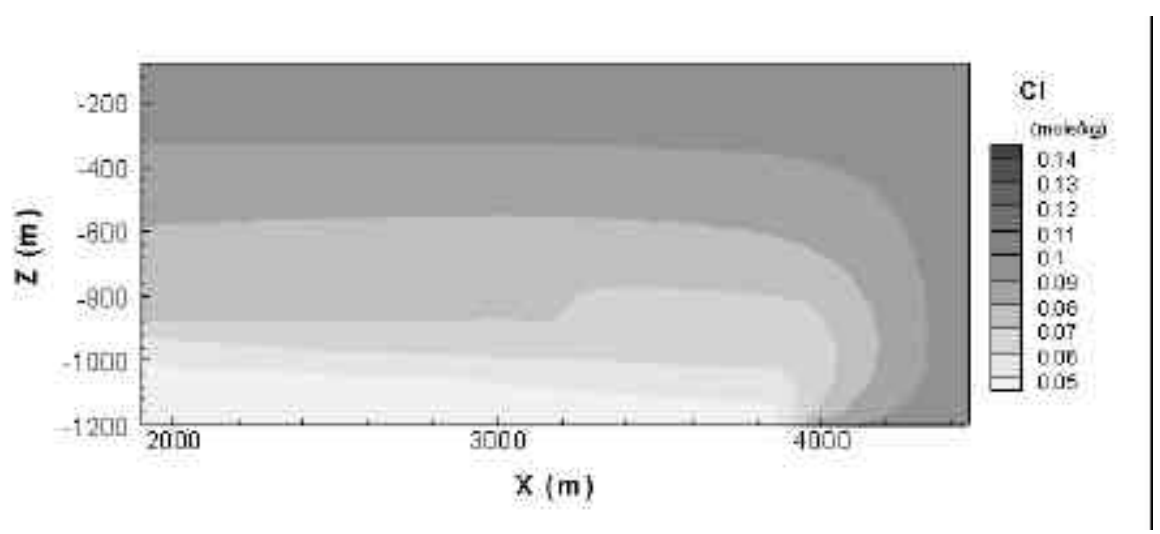

Figure 5.9 Contour plot of $\mathrm{Cl}$ concentration obtained from two-dimensional simulation (10000 years)

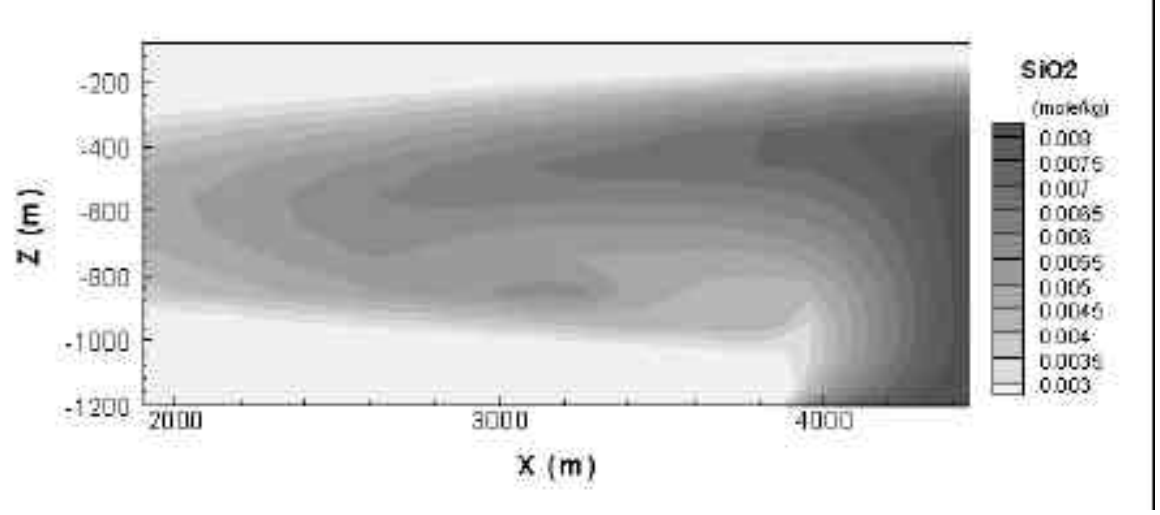

Figure 5.10 Contour plot of $\mathrm{SiO}_{2}$ concentration obtained from two-dimensional simulation (10000 years) 


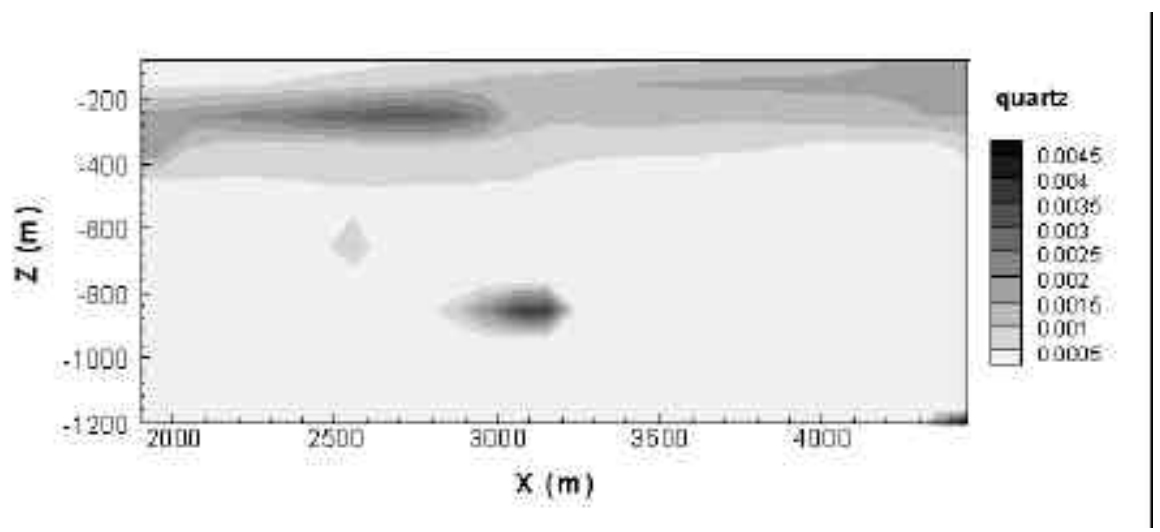

Figure 5.11 Contour plot of quartz volume fraction obtained from two-dimensional simulation (10000 years)

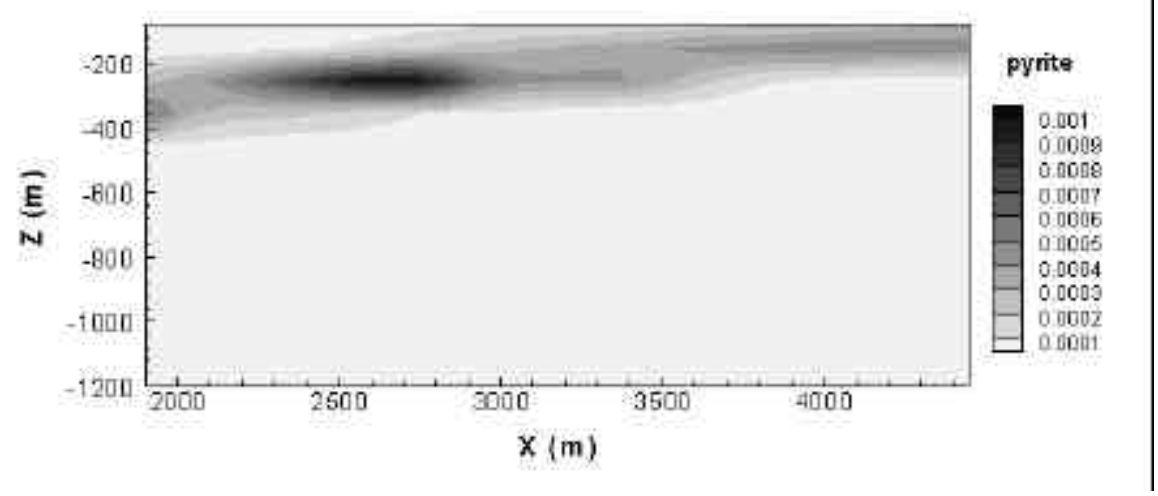

Figure 5.12 Contour plot of pyrite volume fraction obtained from two-dimensional simulation (10000 years)

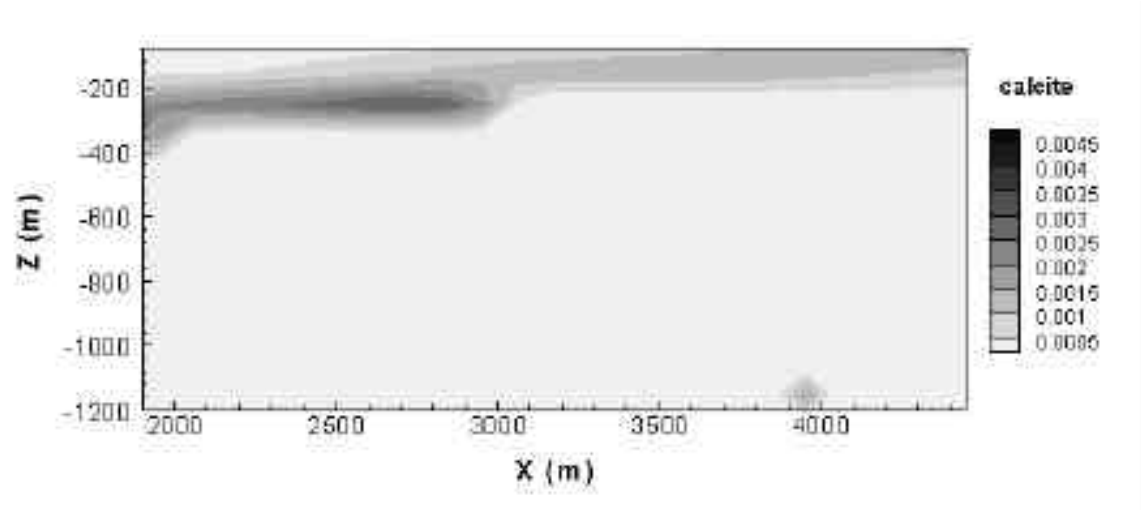

Figure 5.13 Contour plot of calcite volume fraction obtained from two-dimensional simulation (10000 years) 


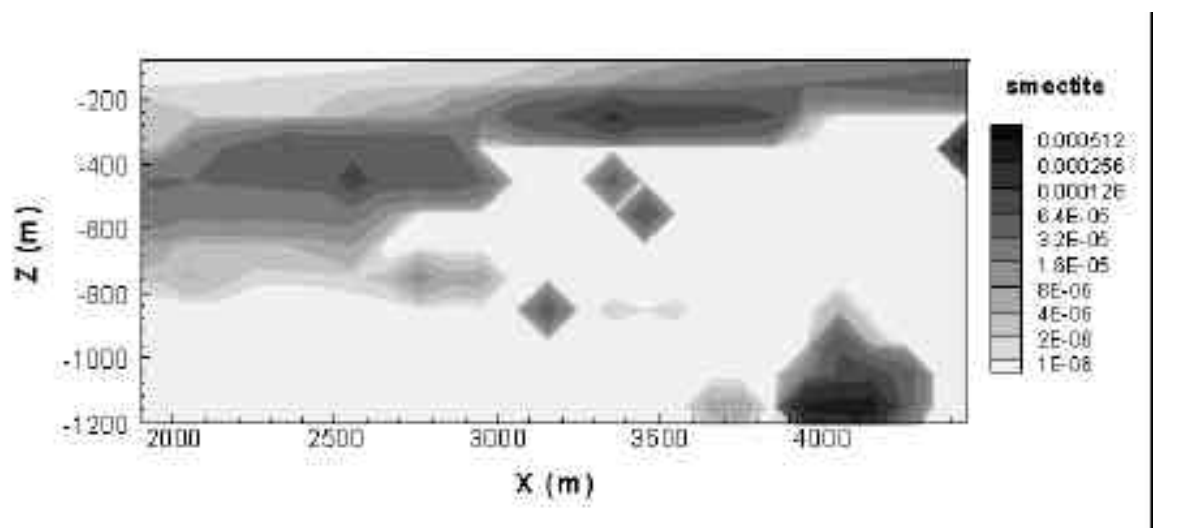

Figure 5.14 Contour plot of Mn-rich smectite volume fraction obtained from two-dimensional simulation (10000 years)

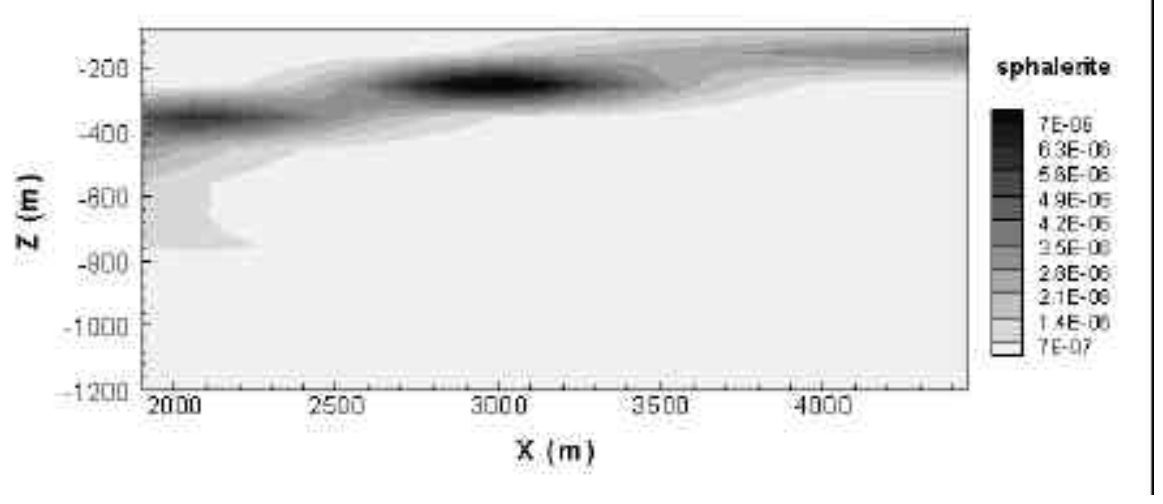

Figure 5.15 Contour plot of sphalerite volume fraction obtained from two-dimensional simulation (10000 years)

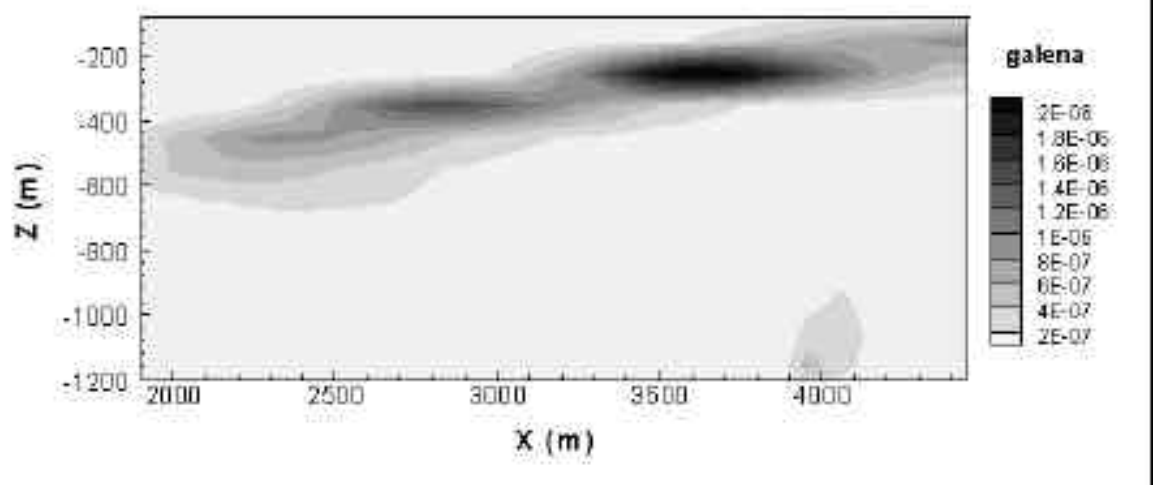

Figure 5.16 Contour plot of galena volume fraction obtained from two-dimensional simulation (10000 years) 


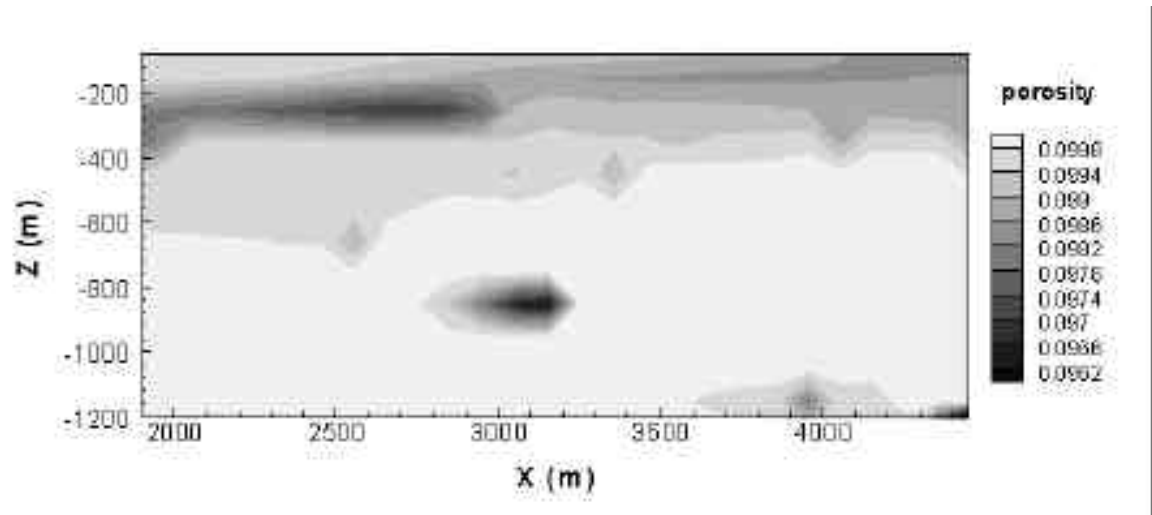

Figure 5.17 Contour plot of porosity obtained from two-dimensional simulation (10000 years)

\section{(2) Production/re-injection simulation}

Mixing behavior due to the injected water in reservoir was simulated to confirm precipitation of Mn-rich smectite and other minerals. The chemical composition of injected water (water separated from reservoir fluid in ambient condition) is shown in Table 4.2. The temperature distribution after 100-years of exploitation is shown in Figure 5.18. The chemical composition such as $\mathrm{pH}$ and chloride near the injection region changes gradually while the temperature decreases (Figures 5.19 and 5.20).

Results indicate that precipitation of Mn-rich smectite, sphalerite and galena as well as quartz (amorphous silica in reality) occurs near the injection region due to mixing of reservoir fluid and the injected water (Figures 5.21 -5.24). Porosity decreases in the injection region (Figure 5.25). Mn-rich smectite, sphalerite and galena have recently been observed in amorphous silica scale formed in re-injection wells and separators. According to Todaka and Tezuka (2002), the reservoir fluid is gradually becoming supersaturated with respect to sphalerite and galena. It is assumed that chemical evolution of the reservoir fluid may be caused by mixing of re-injected water in the reservoir. In addition, anhydrite precipitation occurs in the periphery of the injection region (Figure 5.26). Anhydrite precipitation portion also moves out of injection region with injection. It may be due to change of calcium and sulfate activities. 


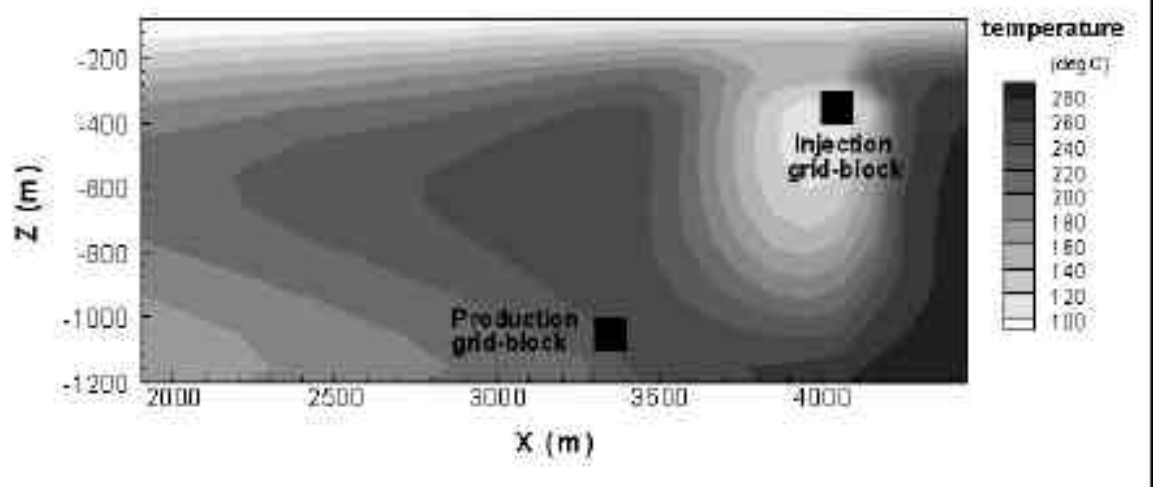

Figure 5.18 Temperature distribution after 100 years from the beginning of production/re-injection

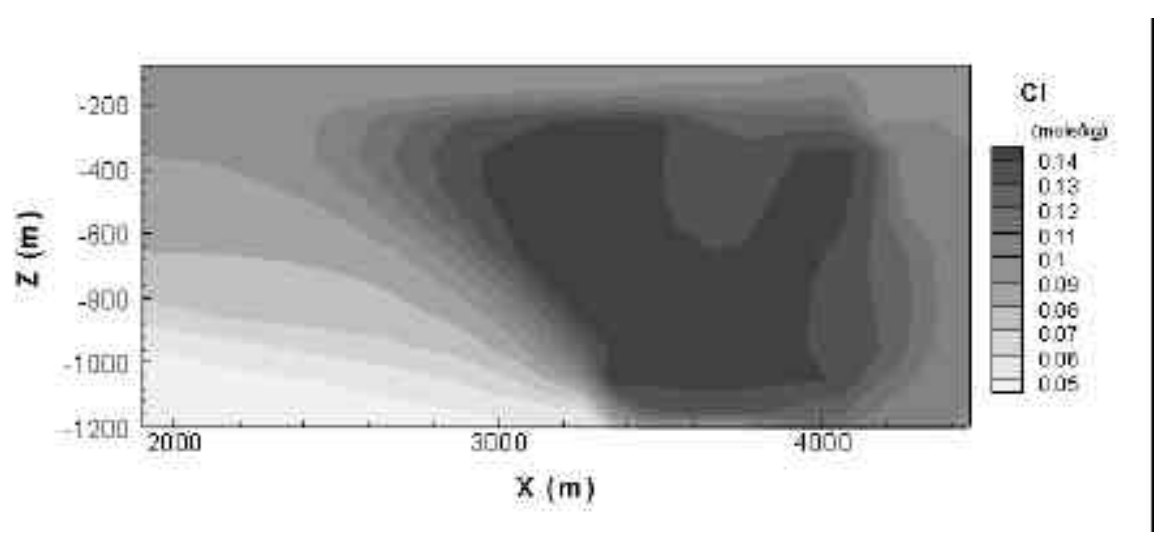

Figure 5.19 Contour plot of $\mathrm{Cl}$ concentration after 100 years from the beginning of production/re-injection

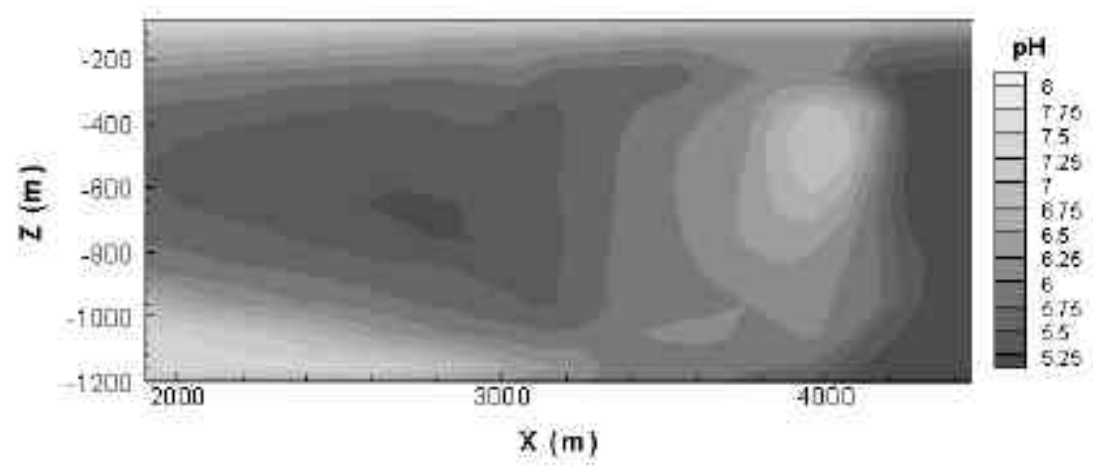

Figure 5.20 Contour plot of $\mathrm{pH}$ after 100 years from the beginning of production/re-injection 


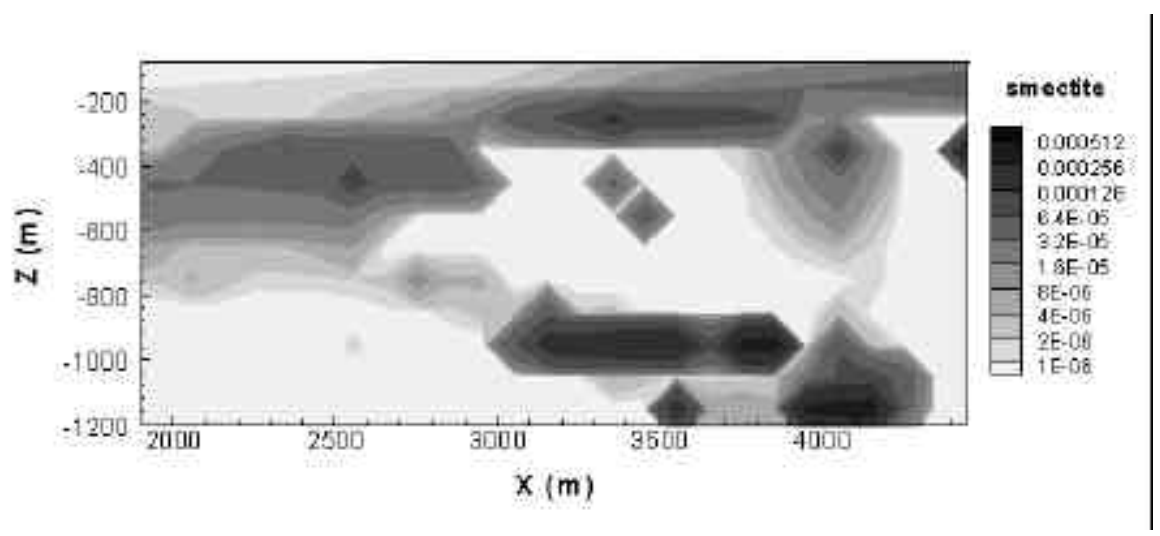

Figure 5.21 Contour plot of Mn-rich smectite volume fraction after 100 years from the beginning of production/re-injection

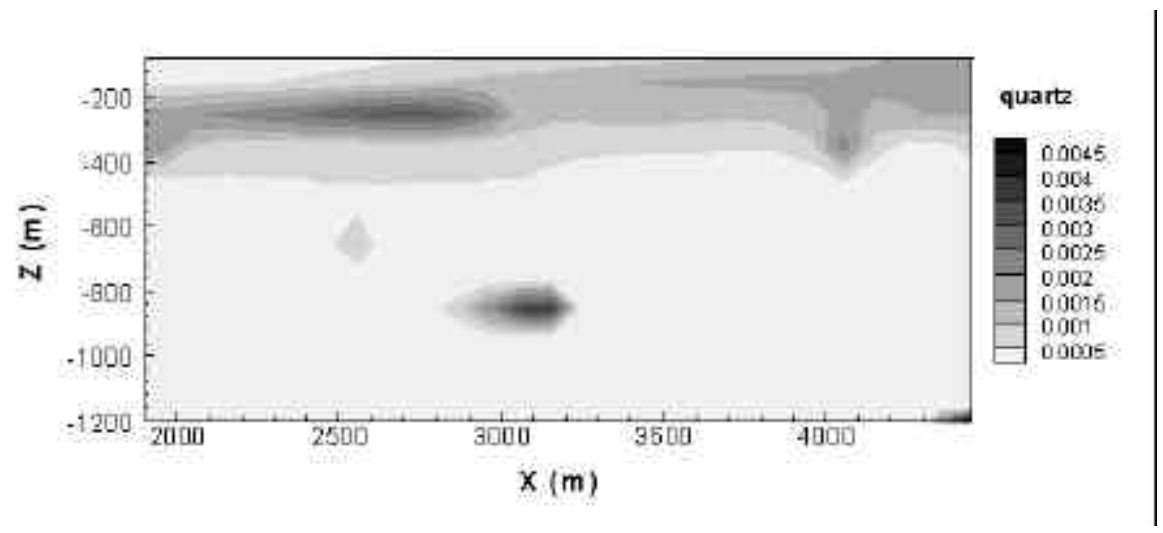

Figure 5.22 Contour plot of quartz volume fraction after 100 years from the beginning of production/re-injection

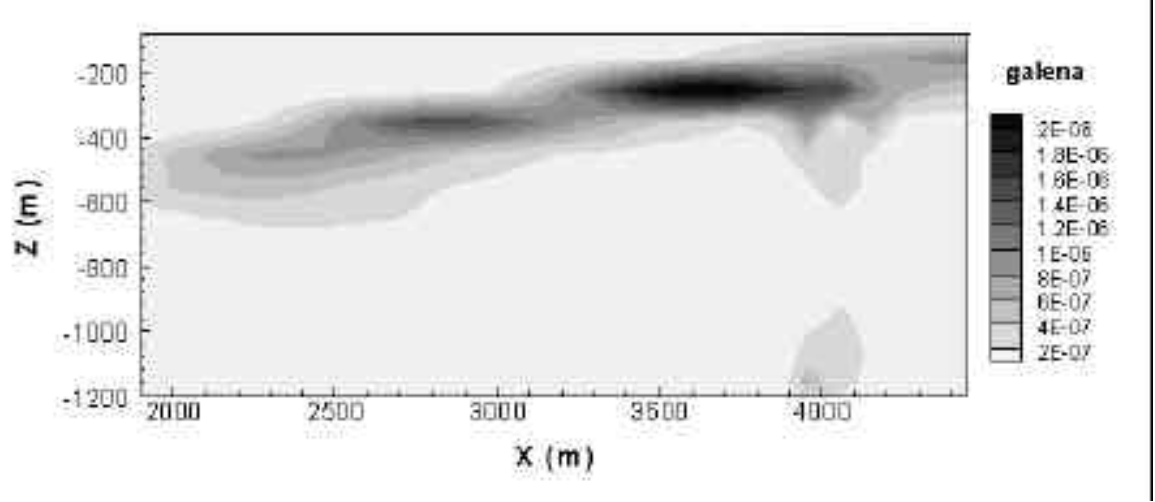

Figure 5.23 Contour plot of galena volume fraction after 100 years from the beginning of production/re-injection 


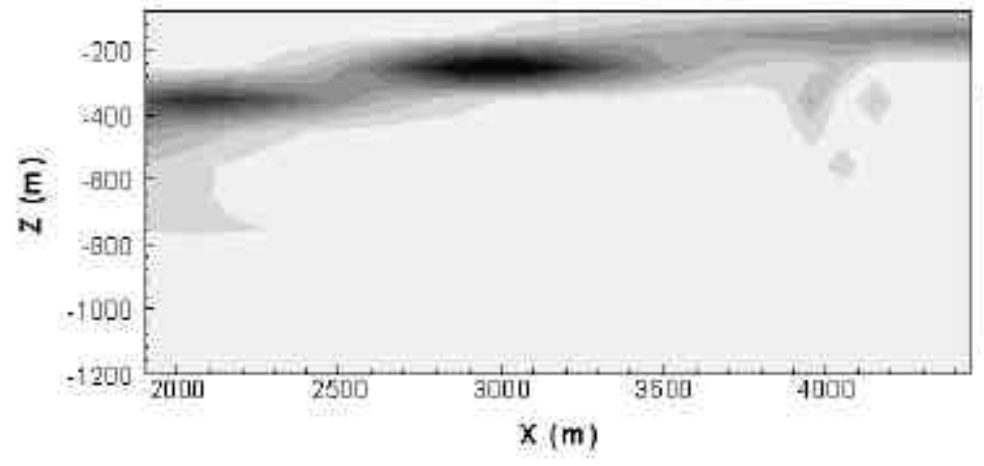

sphalerite

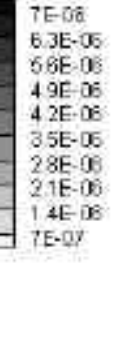

Figure 5.24 Contour plot of sphalerite volume fraction after 100 years from the beginning of production/re-injection

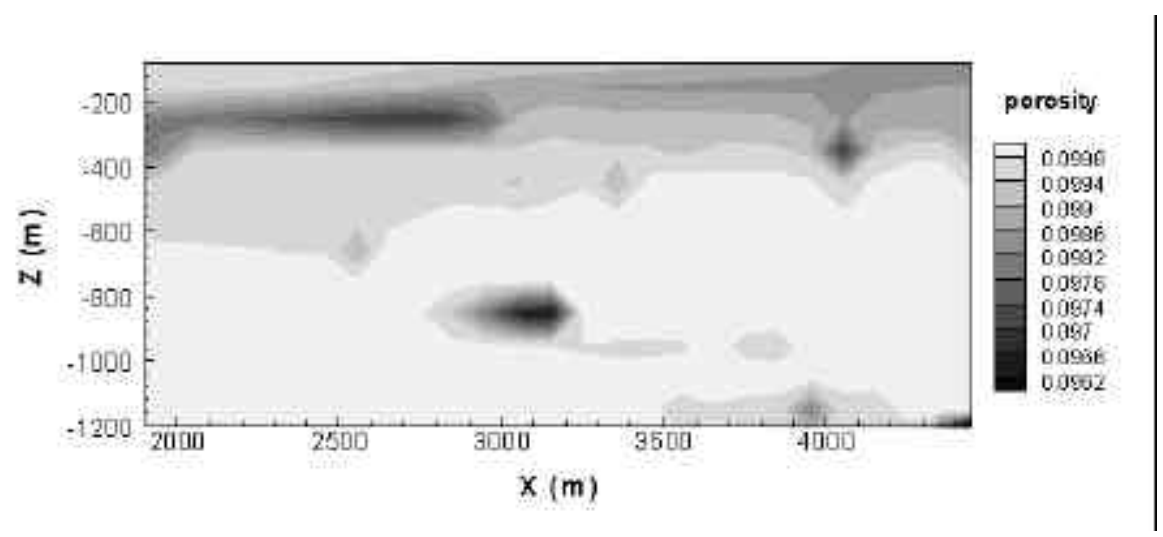

Figure 5.25 Contour plot of porosity after 100 years from the beginning of production/re-injection

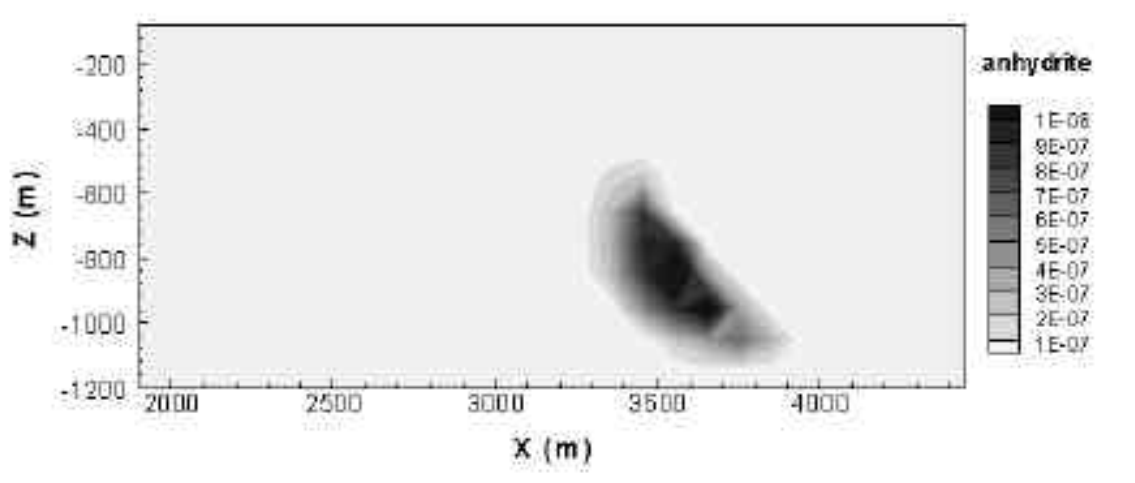

Figure 5.26 Contour plot of anhydrite volume fraction after 100 years from the beginning of production/re-injection 


\section{Conclusion}

We have performed one-dimensional and two-dimensional simulations for chemical interactions between acidic and neutral fluids in the Onikobe geothermal reservoir using reactive geochemical transport simulator TOUGHREACT. The result of two-dimensional simulation is consistent with that of one-dimensional one. Mn-rich smectite precipitates near the mixing front and then dissolves to disappear in the acidic flow zone at higher temperature, but it does not soon dissolve by the acidic water at lower temperature. In the production/re-injection simulation, precipitation of Mn-rich smectite, sphalerite and galena as well as quartz (amorphous silica in reality) occurs near the injection region due to mixing of reservoir fluid and re-injected water. Porosity decreases in the injection region.

$\mathrm{Mn}$-rich smectite precipitation/dissolution relates to $\mathrm{pH}$ and temperature. Precipitation of sphalerite and galena occurs in a similar region as the Mn-rich smectite precipitation. Mn-rich smectite coexists with sphalerite and galena. It is assumed that these minerals are not formed by mineral replacement but by mineral deposition due to mixing of two different types of fluids in open fractures. The changes in porosity and permeability due to precipitation of Mn-rich smectite are small compared with that of quartz, calcite and pyrite. However, the smectite precipitation is likely to fill open fractures and to form an impermeable barrier between regions with acidic and neutral fluids over geologic time.

In addition, quartz, pyrite and calcite clearly precipitate in the shallow zone (cap rock) due to changes in temperature and $\mathrm{pH}$, and porosity and permeability also decrease to develop cap rock.

The present simulation results are specific to the reservoir conditions and parameters considered, and water and mineral compositions used in this study. Precipitation/dissolution of minerals is quite consistent with observation at the Onikobe field. However, some minerals do not precipitate in this simulation even if these minerals are generally observed at the Onikobe field. There are numerous uncertainties such as the chemical kinetics and the lack of sufficiently detailed characterization data at the Onikobe field. Further simulations will be performed to investigate sensitivity to thermodynamic and kinetic parameters, to adjust mineral assemblages.

Acknowledgements. We are grateful to Eric Sonnenthal and Curtis Oldenburg for a review of the manuscript. This work was supported partly by a project provided Electric Power Development Co., Ltd. (Japan), and partly by the Assistant Secretary for Energy Efficiency and Renewable Energy, Office of Wind and Geothermal Technologies, of the U.S. Department of Energy, under Contract No. DE-AC03-76SF00098. 


\section{References}

Abe, M. (1988), “Onikobe geothermal power plant”, Geothermal Fields and Geothermal Power Plants in Japan", International Symposium on Geothermal Energy, Kumamato and Beppu, Japan, November 10-14, 1988, The Geothermal Research Society of Japan, The International Heat Flow Commission of IASPEI, IUGG, 49-56.

Ajima, S., Todaka, N., and Murakake, H. (1998), "An interpretation of smectite precipitation in production wells caused by the mixing of different geothermal fluids", Proc. Twenty-third Workshop on Geothermal Reservoir Engineering, Stanford Univ., 264-269.

Akasaka, C., Nakanishi, S., Todaka, N., and Tezuka, S., (2001), "Twenty-six years of sustained operations at the Onikobe geothermal power plant, Japan”, Geothermal Resources Council, 719-723.

Hardin, E. L. (1998), "Near-field/altered zone models, Milestone report for the CRWMS M\&O”, U.S.Department of Energy, SP3100M4: Livermore, California, Lawrence Livermore National Laboratory.

Johnson, J. W., Knauss, K. G., Glassley, W. E., Deloach, L. D. and Tompson, A. F. B. (1998), "Reactive transport modeling of plug-flow reactor experiments: Quartz and tuff dissolution at $240^{\circ} \mathrm{C} "$, Jour. Hydrol., 209, 81-111.

Johnson, J. W., Oelkers, E. H., and Helgeson, H. C. (1992), "SUPCRT92: A software package for calculating the standard molal thermodynamic properties of minerals, gases, aqueous species, and reactions from 1 to 5000 bars and 0 to 1000 degrees C', Computers and Geosciences, $\mathbf{1 8}$, 899-947.

Narasimhan, T. N. and Witherspoon, P. A. (1976), "An integrated finite difference method for analyzing fluid flow in porous media”, Water Resour. Res., 12, 57-64.

Reed, M. H. (1982), “Calculation of multicomponent chemical equilibria and reaction processes in systems involving minerals, gases and an aqueous phases”, Geochim. Cosmochim. Acta, 46, 513-528.

Sonnenthal, E.L., Spycher, N., (2001), "Drift-scale coupled processes (DST and THC seepage) models”, AMR N0120/U0110 Rev.01, Yucca Mountain Project, Lawrence Berkeley National Laboratory, Berkeley, California.

Steefel, C. I., and Lasaga, A. C., (1994), “A coupled model for transport of multiple chemical species and kinetic precipitation/dissolution reactions with applications to reactive flow in single phase hydrothermal system”, Amer. Jour. Sci., 294, 529-592.

Tardy, Y. and Garrels, R. M. (1974), “A method of estimating the Gibbs energies of formation of layer silicates", Geochim. Cosmochim. Acta, 38, 1101-1116.

Tester, J. W., Worley, W. G., Robinson, B. A., Grigsby, C. O. and Feerer, J. L. (1994), “Correlating quartz dissolution kinetics in pure water fom 25 to $625^{\circ} \mathrm{C} "$, Geochim. Cosmochim. Acta, 58, 
2407-2420.

Todaka, N. and Mezaki, Y., (1999), "Study on silica scale prevention-pH modification technique and geochemical evolution of pH-modified brine in reservoir-“, Chinetsu, 36, 25-40 (in Japanese with English abstract).

Todaka, N and Tezuka, S. (2002), "Utilization of geochemistry for maintenance of geothermal power plant. Water-dominated reservoir: Onikobe geothermal power plant (Geochemistry for geothermal development)", Chinetsu, 39, 60-71 (in Japanese).

Truesdell, A. H. and Todaka, N. (2001), "Chemistry of neutral and acid production fluids from the Onikobe geothermal field, Miyagi Prefecture, Honshu, Japan”, IAEA Meeting.

Walter, A. L., Frind, E. O., Blowes, D. W., Ptacek, C. J., Molson, J. W. (1994), "Modeling of multicomponent reactive transport in groundwater: 1, Model development and evaluation", Water Resour. Res., 30, 3137-3148.

Wolery, T. J. (1992), EQ3/6: "Software package for geochemical modeling of aqueous systems: Package overview and installation guide (version 7.0)", Lawrence Livermore National Laboratory Report UCRL-MA-110662 PT I, Livermore, California.

Xu, T. and Pruess, K. (1998), “Coupled modeling of non-isothermal multi-phase flow, solute transport and reactive chemistry in porous and fractured media: 1. Model development and validation”, Lawrence Berkeley National Laboratory Report LBNL-42050, Berkeley, California.

$\mathrm{Xu}$, T. and Pruess, K. (2001), "Modeling multiphase non-isothermal fluid flow and reactive geochemical transport in variability saturated fractured rocks: Methodology" Amer. Jour. Science, 301, 16-33.

Xu, T., Samper, J., Ayora, C., Manzano, M., and Custodio, E., (1999), “Modeling of non-isothermal multi-component reactive transport in field-scale porous media flow system”, Jour. Hydrol., 214, 144-164.

Yamada, E. (1988), "Geologic development of the Onikobe caldera, Northeast Japan, with special reference to its hydrothermal system”, Rept. Geol. Surv. Japan, 268, 61-190.

Yeh, G. T. and Tripathi, V. S. (1991), "A model for simulating transport of reactive multispecies components: model development and demonstration", Water Resour. Res., 27, 3075-3094. 